\title{
2000 days of SMOS at the Barcelona Expert Centre: a tribute to the work of Jordi Font
}

\author{
Antonio Turiel ${ }^{1}$, Maria Piles ${ }^{1,2}$, Verónica González-Gambau ${ }^{1}$, Joaquim Ballabrera-Poy ${ }^{1}$, \\ Carolina Gabarró ${ }^{1}$, Justino Martinez ${ }^{1}$, Estrella Olmedo ${ }^{1}$, Marcos Portabella ${ }^{1}$, \\ Fernando Pérez ${ }^{1}$, Jordi Solé ${ }^{1}$ \\ ${ }^{1}$ Barcelona Expert Centre. Institute of Marine Sciences, CSIC, Passeig Marítim de la Barceloneta, 37-49. 08003 Barcelona. \\ Spain. E-mail turiel@icm.csic.es \\ ${ }^{2}$ Signal and Communications Theory Department, Universitat Politècnica de Catalunya, Barcelona. Spain.
}

\begin{abstract}
Summary: Soil Moisture and Ocean Salinity (SMOS) is the first satellite mission capable of measuring sea surface salinity and soil moisture from space. Its novel instrument (the L-band radiometer MIRAS) has required the development of new algorithms to process SMOS data, a challenging task due to many processing issues and the difficulties inherent in a new technology. In the wake of SMOS, a new community of users has grown, requesting new products and applications, and extending the interest in this novel brand of satellite services. This paper reviews the role played by the Barcelona Expert Centre under the direction of Jordi Font, SMOS co-principal investigator. The main scientific activities and achievements and the future directions are discussed, highlighting the importance of the oceanographic applications of the mission.
\end{abstract}

Keywords: SMOS; salinity; ocean circulation; oceanography; soil moisture; sea ice; radiometry; remote sensing.

2000 días de SMOS en el Barcelona Expert Centre: homenaje a la labor de Jordi Font

Resumen: SMOS es la primera misión capaz de medir la salinidad superficial del mar y la humedad del suelo desde el espacio. La novedad del instrumento que SMOS lleva a bordo (MIRAS, un radiómetro interferométrico en dos dimensiones que trabaja en banda L) ha implicado el desarrollo de nuevos algoritmos para el procesado de los datos obtenidos. Esto ha supuesto todo un reto, no sólo tecnológico sino también científico, puesto que ha sido necesario abordar diferentes cuestiones inherentes al uso de una nueva tecnología. A raíz del lanzamiento de SMOS, ha surgido una nueva comunidad de usuarios con la correspondiente demanda de nuevos productos y aplicaciones, y un interés creciente en este tipo de nuevos servicios satelitales. En este artículo, se detallan las funciones desempeñadas por el BEC (Barcelona Expert Centre) en la misión SMOS, bajo la dirección de Jordi Font, investigador principal de la parte de salinidad de la misión. Asimismo, también quedan reflejadas las principales actividades de investigación llevadas a cabo en este centro, los logros conseguidos y las futuras líneas de trabajo, destacando la importancia de las aplicaciones oceanográficas de los datos de SMOS.

Palabras clave: SMOS; salinidad; oceanografía; circulación oceánica; humedad del suelo; hielo marino; radiometría; teledetección.

Citation/Como citar este artículo: Turiel A., Piles M., González-Gambau V., Ballabrera-Poy J., Gabarró C., Martinez J., Olmedo E., Portabella M., Pérez F., Solé J. 2016. 2000 days of SMOS at the Barcelona Expert Centre: a tribute to the work of Jordi Font. Sci. Mar. 80S1: 173-193. doi: http://dx.doi.org/10.3989/scimar.04291.15A

Editor: J.L. Pelegrí.

Received: June 15, 2015. Accepted: November 11, 2015. Published: September 30, 2016.

Copyright: (C) 2016 CSIC. This is an open-access article distributed under the terms of the Creative Commons Attribution (CC-by) Spain 3.0 License.

\section{INTRODUCTION}

On 2 November 2009 a Russian Rockot launcher from the Plesetsk Cosmodrome put the European Space Agency (ESA) Soil Moisture and Ocean Salinity (SMOS) satellite into orbit. The SMOS mission is the first of its kind. Its single payload, the Microwave
Imaging Radiometer with Aperture Synthesis (MIRAS) radiometer, is the first-ever $2 \mathrm{D}$ synthetic aperture interferometric radiometer in space operating in microwave L-band. SMOS was designed to fulfil two specific goals: to measure sea surface salinity $(\mathrm{SSS})$ with a $1^{\circ}$ spatial and monthly temporal resolution and a goal accuracy of 0.1 psu over sea (Font et al. 2010a), and to 
measure soil moisture (SM) with a 50-km spatial and daily temporal resolution within a maximum uncertainty of 4\% (Kerr et al. 2010).

SMOS is an explorer mission, which combines scientific challenges both at instrumental and geophysical levels. The SMOS payload, MIRAS, is an interferometric radiometer capable of generating high-resolution, wide-swath snapshots by synthetizing a virtual antenna from an array of small elements (McMullan et al. 2008). By design, the instrument measures the brightness temperature at different polarizations naturally emitted by the Earth at a frequency of $1.4 \mathrm{GHz}$, which corresponds to L-band in the microwave spectrum. The combination of the measured brightness temperatures associated with the same location but from different incidence angles allows geophysical variables of interest to be retrieved by applying an appropriate inversion scheme (Zine et al. 2008). The frequency of $1.4 \mathrm{GHz}$ was chosen because of its high sensitivity to conductivity variations of sea water due to changes in salinity (Klein and Swift 1977) and to variations in SM on land; this frequency has the additional advantage of lying in an electromagnetic band protected from artificial emissions according to international regulations, as this bandwidth is used for space observations in radio-astronomy. However, early in the SMOS mission many issues were apparent: the presence of Radio Frequency Interference (RFI) sources (Oliva et al. 2012), the existence of systematic error patterns in the antenna (Meirold-Mautner et al. 2009, Gourrion et al. 2013), the drift originated by latitudinal and seasonal biases (Oliva et al. 2013) and the considerable extent of land-sea contamination (Corbella et al. 2015). As the mission has evolved, the algorithms have also been improved, tackling all the above issues and including new processing strategies (e.g. complementary calibration procedures such as ALL-LICEF mode).

The oceanographic exploitation of the data has also undergone continuous progress. The first efforts focused on the extensive validation of SMOS data by comparing it with in situ near-surface Argo float observations, and later with data from moored buoys, oceanographic campaigns and thermosalinograph records. Soon SMOS data were employed to study oceanographic processes such as the dispersion of the Amazon plume in the Equatorial Atlantic (Grodsky et al. 2012), the effect of the barrier layer on hurricane intensification (Reul et al. 2014), the dynamics of rain lenses on the sea surface (McCulloch et al. 2011), the predictive value of salinity for El Niño/Southern Oscillation forecasting (Ballabrera et al. 2013) and the evolution of cold-core rings in the Gulf Stream (Umbert et al. 2015). New applications appear by the day, one of the most promising fields being the study of sea ice (Kaleschke et al. 2012) and the estimation of strong winds in tropical tempests (Reul et al. 2012).

The Barcelona Expert Centre (BEC) was created in 2007 to provide support to the Spanish SMOS activities (Camps et al. 2016). BEC's missions were to provide assessment to ESA as a Level 2 Ocean Salinity Expert Support Laboratory, to contribute to SMOS radiometric calibration and validation activities, and to develop and validate new algorithms for the generation of added-value products at Levels 3 and 4, helping the CP34 dedicated Spanish production centre to maintain the operational generation and distribution of SSS and SM products. During the last few years, BEC's missions and commitments have evolved. The most significant change happening in 2013, when the operations at CP34 were discontinued and BEC took over. As BEC started the generation and distribution of SSS and SM products, some deep, useful changes with respect to the structure of the former CP34 were accomplished: a new, easyto-navigate page was put in place; the structure of the products was simplified and unified under the netCDF format in the Climate and Forecast convention to better meet the needs of the scientific community. The data produced at BEC are freely distributed to the scientific community by means of the OPENDAP, HTTPServer and NetcdfSubset services through a THREDDS server. Maps produced by BEC can also be visualized online by means of our Web Map Service, developed by the Reading e-Science Centre (Blower et al. 2009). New products and new applications were made available: the new CP34-BEC service was created. BEC's visibility increased enormously thanks to those changes, and now $\mathrm{BEC}$ is a reference in the processing and distribution of marine remote sensing products in Spain. From its inception until January 2016, Professor Font has headed BEC, which is currently the result of intense work by Professor Font to give the Spanish contribution to SMOS a stable framework. Jointly with Professor Yann Kerr, Professor Font is the co-Principal Investigator of the SMOS mission, and has been in charge of the sea salinity part of the mission for the last 17 years. Thanks to his tireless commitment to SMOS and BEC, both the mission and the centre have steadily progressed over the years to the present day. With the help and support of the Spanish Ministries of Science, Education and Economy, and the extensive support of the Spanish Centre for Technological and Industrial Development (CDTI), Professor Font was able to lead a successful Earth observation mission, which not only represented a major scientific achievement but also a boost for scientific Earth observation and aerospace industrial sectors in Spain.

Under Jordi Font's attentive and involved direction, BEC has thrived: a human team of 16 persons have carried out the scientific and operational activities in all processing levels of the mission, with significant contributions even in the SM part of the mission. As Head of BEC, Jordi Font granted stable funding and a meticulous supervision of the research activities (participating in all the scientific discussions and providing new lines of research). Moreover, he boosted SMOS operations in Spain, first through the continuous scientific and technical support to the Spanish centre for the production of high-level SMOS products, CP34, and later, when the funding of CP34 was discontinued, by broadening BEC's activities to include the operational activities of CP34 and even increasing the number of products and services. During the eight years since the creation of BEC, Professor Font has been involved in the many aspects of BEC's daily activity, from the small details to the major plans and the future lines, 
[K]

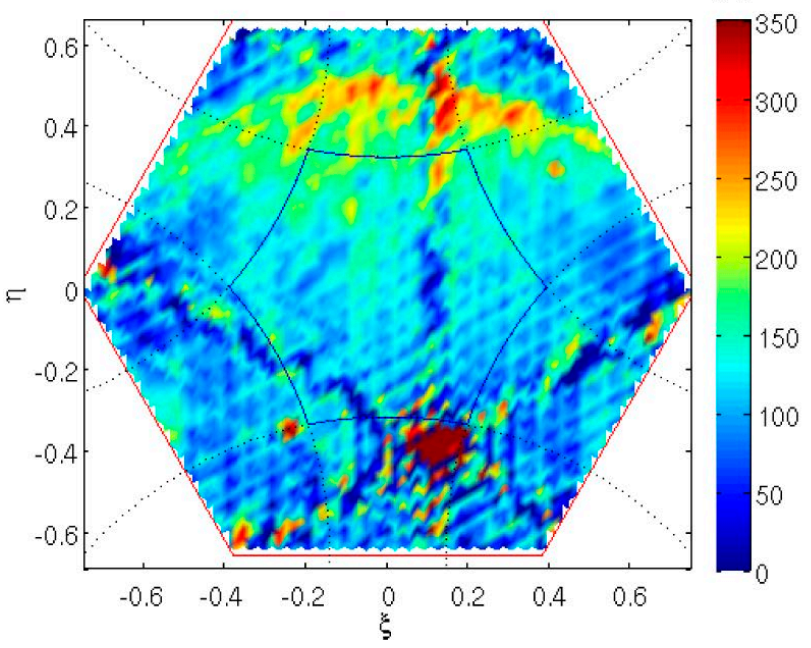

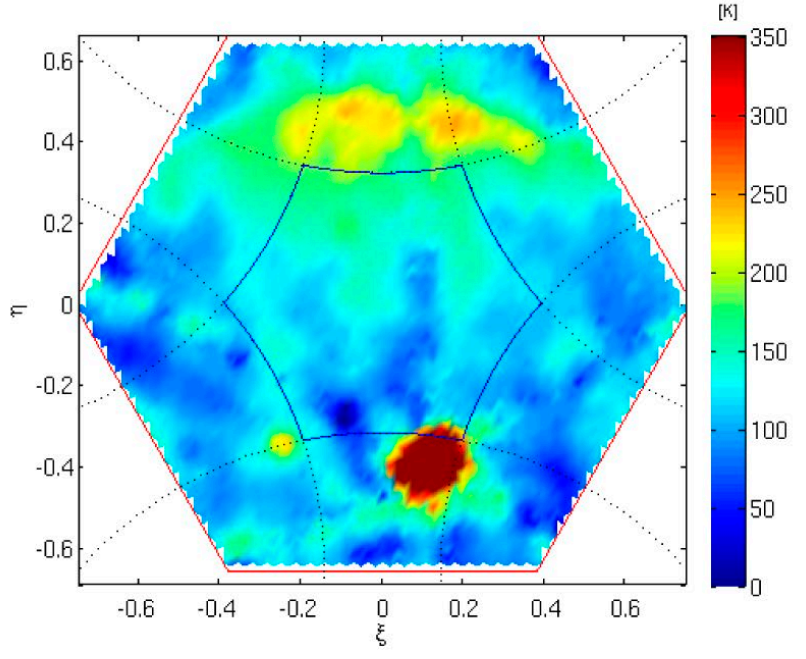

Fig. 1. - Brightness temperatures in the fundamental hexagon of a snapshot over the Atlantic Ocean strongly affected by an RFI (Radio Frequency Interference) produced by a ship, Y-polarization. Left, nominal TB; right, nodal sampling TB (Brightness Temperature). A clear reduction of the general ripples and the sidelobes along the RFI directions can be appreciated using the nodal sampling technique.

always providing a deep insight into the problems, always serving as a link with the other international research labs and the ESA, and always providing a ready helping hand. Finally, Professor Font's human dimension, generosity and kindness also made a great contribution to the success of SMOS and BEC.

This paper is a review of the main scientific achievements and the future lines of research at BEC, intended to be not only a tribute to Jordi Font at the time of his well-deserved retirement but also a useful compilation of the main past and future research directions at BEC, in SMOS and in passive microwave radiometry in general. At the time of writing, Jordi is still participating in the scientific discussion of all the activities described below, some of them started some years ago, some of them dating from a few months ago.

The paper is structured according to the main processing levels of SMOS, each with one section, from Level 1 to Level 4. Finally, the conclusions are presented.

\section{L1 ACTIVITIES}

\section{Radio frequency interference detection and mitigation}

Early after launch, many sources of RFI were found. The impact of RFI on SMOS snapshots is quite large: a typical source of several thousand Kelvin induces sidelobes of several tens of Kelvin or more along the three main directions of the SMOS hexagonal grid, producing ripples all over the image (see, for instance, the left panel in Fig. 1). The presence of RFI is a serious issue, especially over sea, as the variations of brightness temperature related to the natural geophysical variability of the oceans are of a few Kelvin and so cannot be correctly estimated if RFI corrupts the image; even on land RFI is quite disturbing (and most RFI is on land). For that reason, since the beginning of the mission RFI has been one of the most important prob- lems for SMOS and the successive missions operating in L-band (NASA Aquarius and Soil Moisture Active Passive (SMAP) missions). The continuous efforts by ESA to spot and force the switch-off of those illegal emissions have significantly reduced their number, but RFI contamination is still a quite pervasive, serious issue (Oliva et al. 2012). This situation has led to intense activity to develop new algorithms for detecting and mitigating RFI (Daganzo-Eusebio et al. 2013, Park et al. 2015), a permanently on-going effort that will also benefit future Earth observation missions. BEC has been collaborating in the development of a novel algorithm focusing on RFI source localization for synthetic aperture interferometric radiometers such as MIRAS. The method uses Direction of Arrival estimation techniques for high angular resolution RFI detection (Park et al. 2015).

\section{Nodal sampling}

Not only RFI sources but also Sun contamination and, in general, any sharp transition in the brightness temperature scenes produces Gibbs-like contamination that makes the correct retrieval of SSS quite complicated. In order to improve these artefacts, BEC is working on a novel brightness temperature reconstruction algorithm called nodal sampling (NS) (González-Gambau et al. 2016). In the most general case, the signal to be retrieved is a mixture of the geophysical signal and the perturbation induced by some sources. This technique is based on, first, oversampling the image (by increasing the number of points in the spatial frequency space through zero-padding the Fourier coefficients at the non-sampled spatial frequencies) and, then, sampling the signal with the same rate of spatial points but choosing them where eventual punctual perturbations cancel without strongly altering the value of the geophysical signals. A recent improvement of the technique, just introduced at BEC, improves the quality of the reconstructed image by allowing some flexibility in the area 
of search for the nodal point. An example of an RFI over the Atlantic Ocean can be seen in Figure 1, where the image using the current SMOS image reconstruction approach and the image processed using NS can be compared. NS significantly reduces the sidelobe levels in the directions of the RFI source and also enormously reduces the general ripples all over the image.

BEC has performed an extensive validation of the NS technique by comparing modelled brightness temperatures (Zine et al. 2008) with brightness temperatures reconstructed in the standard way or using NS. Our tests have revealed that the standard deviation of the difference between measurements and model is reduced by about $1.6 \mathrm{~K}$ over clean and stable zones when NS is used in comparison with the nominal case; this reduction is approximately $1 \mathrm{~K}$ when the technique is applied and validated at a global scale, and thus a significant improvement in the retrieved salinity is expected. BEC's newest algorithms developed for assessing the impact in performance brought about by any change in the L 1 processor have been extensively applied in the case of NS. Instead of inverting a multiparametric cost function that includes the observed brightness temperatures at multiple incidence angles (see section on Level 2 activities), the brightness temperature coming from a point with a given incidence angle has been considered as an independent source of information on SSS, effectively introducing a singleangle SSS retrieval (this method is explain in greater detail in the next section). Single-angle SSS retrievals consist in fixing all the auxiliary parameters (sea surface temperature (SST), wind speed, Total Electron Content) except SSS, and then retrieving SSS by minimizing the difference between the measured TB and the modelled ones. The auxiliary parameters are fixed to the value provided as first guess from independent sources (typically, data from the European Centre for Medium-Range Weather Forecasts (ECMWF)), so they have an inherent error that adds up to the error in the measurement of the brightness temperature, increasing the uncertainty on the value of SSS provided by single-angle SSS retrievals. Then, all the retrievals of SSS for the same location obtained at different incidence angles during a given period of time (in this case 9 days) are accumulated to construct a histogram of retrieved SSS's for each geographical point; this histogram is very revealing about the quality of brightness temperatures as a source of information on SSS. These histograms reveal that the introduction of NS leads to a mean reduction of around $1.7 \mathrm{psu}$ in the standard deviation of the SSS distributions in comparison with the distribution of the nominal SSS (Fig. 2), which means that NS leads to more accurate measurements of SSS. Currently, the investigation is focused on several improvements at algorithm level, on the assessment of the geophysical content of TB images based on the correspondence of singularity exponents (Turiel et al. 2009), and on quality assessment over land (comparison with the theoretical model).

\section{ALL-LICEF mode assessment}

MIRAS was built with three noise injection radiometers (McMullan et al. 2008) to ensure a stable and accurate measurement of the zero baseline visibility. In-orbit experience has shown that a similar level of performance can be achieved using only the LICEF receivers (ALL-LICEF mode), with the advantage of a significantly simpler calibration concept. The zerospacing visibility is computed in this mode as the mean antenna temperature estimated by the 69 power detectors in each individual receiver, according to the onepoint calibration scheme (Torres et al. 2008).

The performance of this mode of operation needs to be thoroughly assessed before it becomes operational and can be implemented in ESA's official processor. In this context, BEC is actively working on the assessment of the performance of the ALL-LICEF mode. This activity includes the evaluation of the long-term stability of ALL-LICEF antenna temperatures. From this analysis, certain small deviations have been detected in some receivers, leading to the study of a selected-LICEF approach instead of the ALL-LICEF mode (filtering the receivers showing anomalies, as can be observed in Figure 3). The impact of this LICEF selection on the mean antenna temperature has been analysed. Figure 3 (right plot) shows the mean antenna temperature difference between ALL-LICEF and selected-LICEF modes
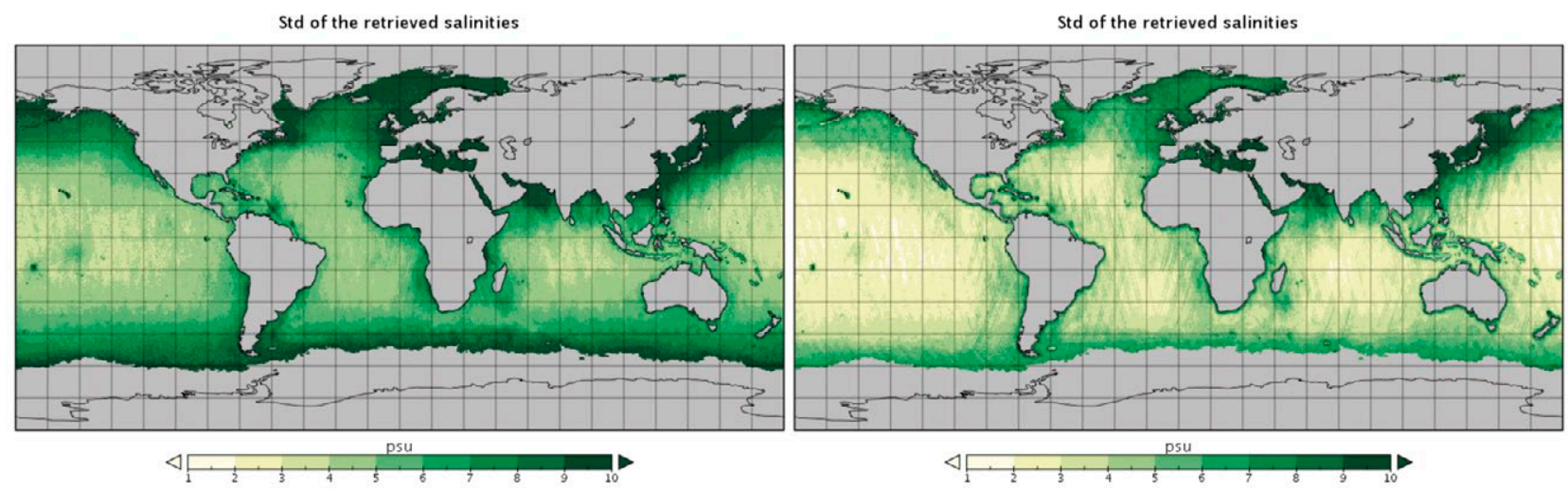

Fig. 2. - Maps of the standard deviation of single-angle SSS (Sea Surface Salinity) distributions. Left, SSS from nominal TB; right, SSS from nodal sampling TB. A reduction of $1.7 \mathrm{psu}$ (practical salinity units) in the standard deviation of SSS distributions is obtained at a global scale when using the nodal sampling technique. 


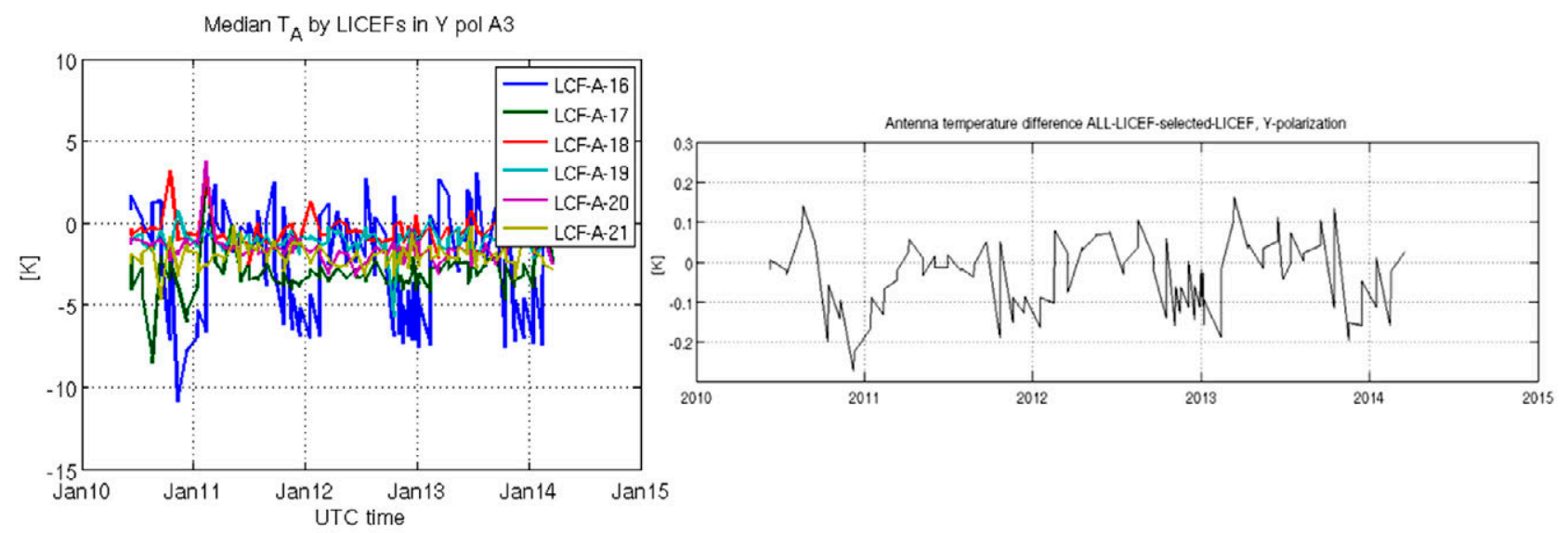

Fig. 3. - Left, antenna temperature variations corresponding to receivers located in segment A1 in Y-polarization when compared with the antenna temperature averaged from all the LICEFs. Anomalous drifts can be clearly observed in some periods of the long-term dataset for receiver LCF-A-16. Right, antenna temperature difference between ALL-LICEF and selected-LICEF modes.

for Y-polarization. It can be concluded that using the selected receivers produces a non-negligible difference in the mean antenna temperature computation in comparison with the ALL-LICEF solution and corrects a systematic/seasonal error that would otherwise be observed. Further work is dedicated to the evaluation of the temporal stability of ALL-LICEF brightness temperatures at orbital (differences between ascending/descending overpasses), seasonal and yearly time scales, in terms of bias and spatial ripples. The ongoing study will include the generation of full Hovmöller plots (a dense set of orbits over the whole mission duration to study the temporal stability).

\section{Latitudinal and seasonal amplitude calibration assessment}

Since the end of the Commissioning Phase, MIRAS has proven to perform well within the accuracy and radiometric sensitivity requirements (Corbella et al. 2011), which is paramount for quality retrievals of the geophysical parameters. However, the receivers of the instrument show some orbital and seasonal drifts,

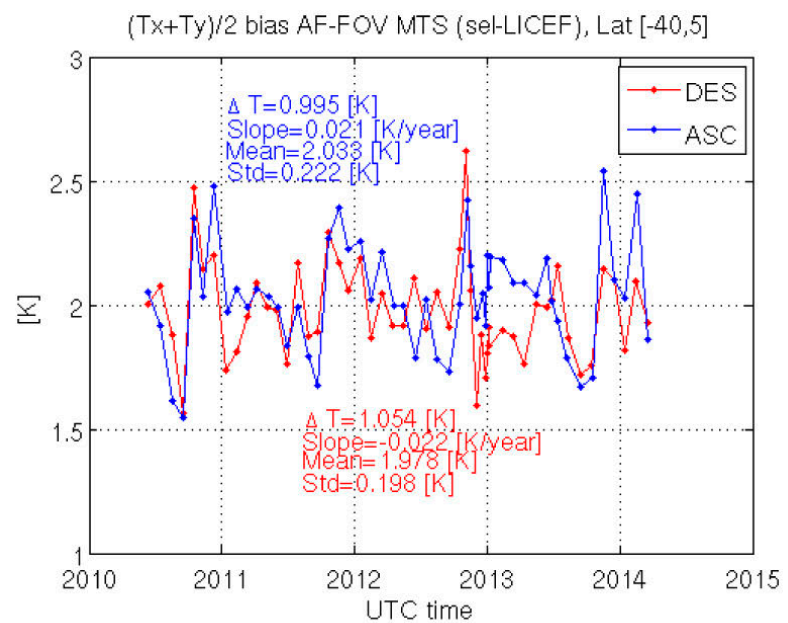

as revealed by the analysis of brightness temperature stability over a full year cycle (Oliva et al. 2013). The consistency of the amplitude calibration is a crucial issue in an interferometric radiometer such as MIRAS, since it has a major impact on the sensor stability (Torres et al. 1996, Corbella et al. 2005). Therefore, these drifts need to be compensated.

Several methodologies and tools have been developed to evaluate the short- and long-term amplitude calibration consistency (González-Gambau et al. 2014). This assessment can be performed at the calibration stage but also once the brightness temperature has been produced. BEC has the capability of evaluating the impact on the brightness temperature and also on the SSS retrievals of the different modifications/improvements/ new algorithms that can be introduced at calibration and image reconstruction levels. As part of this activity, we are currently working on the comparison of brightness temperatures from ALL-LICEF mode and the current Level 1 version using a common set of metrics (L1 Team 2015), such as the brightness temperature stability over the ocean. Figure 4 shows the mean first Stokes brightness temperature bias (difference between meas-

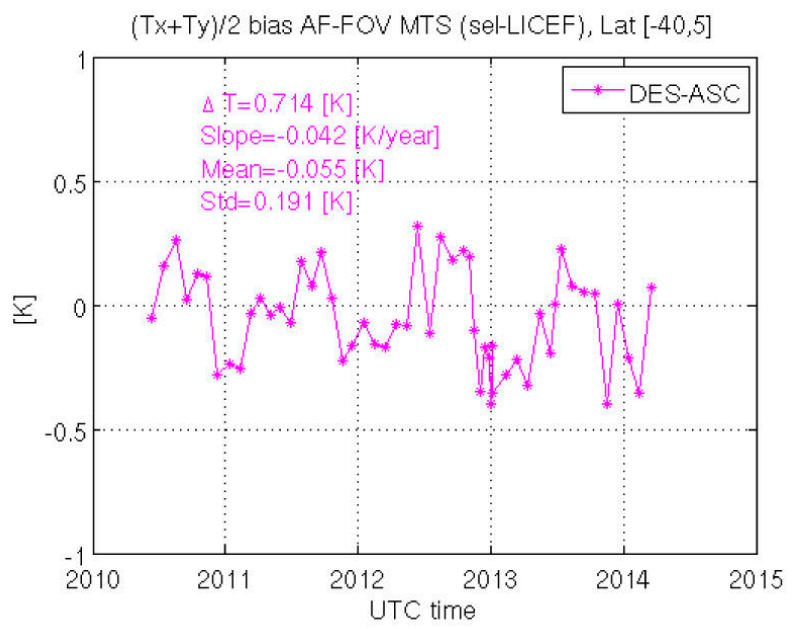

Fig. 4. - Assessment of brightness temperature long-term stability over ocean. Left, first Stokes TB mean bias (difference between the measurement and the model) in the AF-FOV (Alias-Free Field of View) for ascending/descending orbits. Right, difference between ascending and descending bias. 
urements and model) in the AF-FOV (alias-free field of view) region for ascending/descending orbits (left plot) separately. The difference between ascending and descending orbits is also shown (right plot). The metrics and differences mentioned above allow us to evaluate the improvements of the new algorithms on the stability of the brightness temperature products and therefore on the geophysical retrievals.

\section{Impact of the calibration frequency of the local oscillator}

Errors in the phase of the local oscillators (LO) used to maintain the operating frequency of the MIRAS receivers drifts over time, resulting in a blurring of the reconstructed brightness temperature (TB) image. At the end of the commissioning phase, it was decided to calibrate the LO every 10 min while waiting for a more in-depth analysis. During short periods of time, the LO calibration was performed every 2 min to assess the impact of a higher calibration rate on the quality of the data. In Gabarró et al. (2013) it was shown that the LO calibration frequency has a noticeable impact on brightness temperature: a 10min calibration frequency leads to across- and alongtrack error patterns of $\pm 0.3 \mathrm{~K}$ in comparison with the TB reference (corresponding to 2-min calibration frequency). A simulation experiment confirmed that the presence of such systematic patterns is due to the visibility phase errors induced by the LO calibration rate. These patterns are propagated into the SSS retrievals; overall, the SSS error increase (10-min relative to 2-min SSS data) is about 0.39 and 0.14 psu for the 10- and 6-min data sets, respectively.

\section{L2 ACTIVITIES}

The Level 2 processor uses geolocated brightness temperature (TB) Level 1C products to retrieve SSS using an iterative scheme (Zine et al. 2008). This algorithm starts from a first SSS guess that is applied in a forward model to get a first estimate of TB. The forward model consists of a given geophysical model function that relates the geophysical parameters defining the radiometric state of surface water (SSS, SST, surface roughness) with the geophysical TB, and then transforms this geophysical TB to include all other non-geophysical terms, corrections and transformations, leading to a value of TB as measured by SMOS in its own antenna reference frame (Gabarró et al. 2004, Guimbard et al. 2012). The differences between the observed and the modelled TB are accounted for in an appropriate cost function, and then an iterative scheme is applied to improve the retrieval of SSS and the other parameters by minimizing this cost function, thus providing the retrieved SSS at a given grid point (Gabarró et al. 2009, Talone et al. 2009, 2011). For a given geolocalization, the cost function accounts for all the measurements of TB acquired during a given orbit for that particular point in ocean, which differ from each other in the incident angle, azimuth and polarization.
Below we will explain in detail the contributions by $\mathrm{BEC}$ to the different stages in L2 processing mentioned above.

\section{Ocean forward model}

The contribution of SSS to the water-leaving radiance in the L-band, also known as the flat sea contribution (Klein and Swift 1977), is not the only one present on the ocean surface; it is thus necessary to identify all contributions to the measured TB. Depending on the minimization method applied and the particular chosen cost function, each of the contributions to TB will change at each iteration. The main contributions to the measured TB, apart from SSS and SST, are the roughness of the sea surface and the foam contained in each portion of the ocean surface (Guimbard et al. 2012), and the L-band emission by the atmosphere towards the ocean surface. Other contributions must also be accounted for in order to attain the precision required by final users. First, some sources of glint (the Sun, Moon and the Milky Way being the main contributors) must be estimated. In the case of the Milky Way, a precise knowledge of the sky map is necessary, but we also need a good model to describe how wind affects the scattering of its radiation over the ocean (Tenerelli et al. 2008). A similar phenomenon takes place due to Sun glint over the sea surface (Reul et al. 2007). However, the orientation of the satellite with respect to the Sun implies that the centre of the Sun's glitter pattern will never be located in the field of view of SMOS and its contribution to the measured TB is only non-negligible around the winter solstice in some parts of the field of view for acquisitions located in the Southern Hemisphere in descending orbits. All these contributions are modelled depending on the position and orientation of SMOS and the expected sea surface temperature, wind speed and wind direction at the moment at which the measure was taken, also taking into account other quantities such as the atmospheric temperature, pressure and water vapour content of the atmosphere. Therefore, a good quality set of auxiliary data is essential to produce a good quality SSS data set.

Once these contributions have been evaluated at the sea surface level (known as bottom of the atmosphere) it is necessary to express them in the ARF because the TB is measured by SMOS at $750 \mathrm{~km}$ from the Earth's surface. In its travel towards the satellite, the radiation suffers attenuation due to the presence of the atmosphere and two different rotations: a geometrical rotation due to the rotation of the polarization basis and a Faraday rotation due to the presence of the ionosphere. In addition, the emission of the atmosphere towards SMOS must also be computed to obtain an accurate solution during the minimization of the cost function. These transformations involve the estimation of the total electron content (TEC) of the atmosphere (using standard measurements of the solar flux) at the time of the measure acquisition (Crapolicchio et al. 2008) and the knowledge of the terrestrial geomagnetic field model, which is updated every five years (Thébault et al. 2015). 


\section{Ocean target transformation}

One of the pitfalls found in the generation of the early level 1 products was the existence of large residual biases between measured TBs and modelled ones. These biases translate at level 2 into up to 3 psu near the centre of the track, and they are characterized by their spatial distribution at snapshot level. Due to the different antenna patterns and the error associated with their initial measurement and possible drifts during the mission, a minimum reconstruction error inherent to the inversion algorithm exists, leading to spatial biases. To correct these systematic biases, the ocean target transformation (OTT) (Meirold-Mautner et al. 2009, Font et al. 2010b, Corbella et al. 2013) was introduced in the ESA operational production chain as well as in the BEC research chain. This procedure assumes that in a very stable zone the measured SSS must be very close to that given by the World Ocean Atlas (WOA), and that the errors associated with the other auxiliary parameters (provided by model forecasts from ECMWF) are negligible. Then, the OTT is defined as the average, at snapshot level, of the difference between the modelled TB (assuming SSS as that provided by the WOA) and the measured TB, both evaluated in this zone (Tenerelli and Reul 2010). Once these systematic biases of the synthetic antenna are known, they can be corrected by subtracting the OTT from the measured TB. The zone at which OTT is computed is taken far from any land mass to minimize disturbances; to this end, L2 teams chose a zone located in the south central Pacific.

During the last two years, BEC has devoted part of its research work in this field to decreasing the residual variability of the OTT by introducing model-independent techniques (Gourrion et al. 2013). We are presently studying other approaches, which include considering the OTT not as an additive term but as a matrix derived from SMOS data, which would be responsible for inducing long-range correlations in the antenna in the form of point spread functions (work in progress).

\section{Sea surface roughness model}

In 1998, once the SMOS mission had been approved by ESA, many unanswered questions were raised, and in particular the effect of sea roughness on emissivity at L-band. To clarify this unexplored issue, the WISE campaign was carried out in 2000 and 2001 to establish under real field conditions the empirical relation between L-band radiometric data and a set of key sea surface geophysical parameters such as salinity, temperature and roughness. These campaigns took place during one month each year at the Casablanca oil rig, $40 \mathrm{~km}$ from the coast of Tarragona, Spain (Camps et al. 2004). From these datasets, two empirical roughness emissivity models were derived (Camps et al. 2004, Gabarró et al. 2004). The experiments showed that wind direction has a very low effect on L-band emissivity, except in the case of very high winds.

Much has changed since those early developments. Presently, the operational processor incorporates an empirical roughness model that has been derived from actual SMOS data, using an empirical function which has been fitted from SMOS TBs and co-located wind speed values obtained from ECMWF analysis (Guimbard et al. 2012). The continuous improvements of the SMOS TB make necessary to revisit this empirical approach periodically. Currently a new update of the roughness model is being performed to account for the changes in TB quality (release v620, which has recently become operational). The new version of the operational roughness model includes an improved neural network with 10 neurons, an iterative scheme to progressively improve the quality of the roughness term, and the introduction of an appropriate filtering scheme to avoid the bias induced by outlier conditions.

\section{Sea surface salinity retrieval}

The inversion problem (that is, inferring a sensible estimate of the salinity at a given geolocalization given a collection of observed brightness temperatures acquired at different incidence angles and polarizations) is not straightforward, and substantial effort has been required to define the most appropriate cost function and minimization strategy. Several Bayesian-based configurations of the cost function were examined, depending on whether a priori information was used for the inversion or not, with a specific discussion on the role of the priors on the final solution. Prior to launch, the SMOS end-to-end simulator was used to test the accuracy of different cost function configurations (Gabarró et al. 2009, Talone et al. 2009); as a result the cost function was defined and finally included in the operational processor, in addition to the minimization algorithm (Levenberg-Marquad). These studies concluded that a cost function derived by Bayesian inference (which is also the maximum likelihood estimator if the errors are assumed to be Gaussian-distributed) was the best choice for retrieving salinity from observations. The cost function $f(S S S)$ then has the form:

$$
\begin{gathered}
f(S S S)=\sum_{n} \frac{\left(T_{B}^{\text {meas }}\left(\theta_{n}\right)-T_{B}^{\text {mod }}\left(\theta_{n} ; S S S, S S T, w\right)\right)^{2}}{\sigma_{T_{B}}^{2}\left(\theta_{n}\right)}+ \\
+\frac{\left(S S S-S S S_{0}\right)^{2}}{\sigma_{S S S}^{2}}+\frac{\left(S S T-S S T_{0}\right)^{2}}{\sigma_{S S T}^{2}}+\frac{\left(w-w_{0}\right)^{2}}{\sigma_{w}^{2}}
\end{gathered}
$$

where the first term refers to SMOS observations (measured brightness temperatures) while the other three summands are constraints to the prior values (subindexed with 0); each term is normalized by its known or estimated uncertainty.

Much effort has been dedicated to examining whether the inclusion in the retrieval procedure of some prior information on the value of the salinity (typically, the climatological value) would lead to better SMOS salinity retrievals or, on the contrary, that constraint could be a damper on the actual signal conveyed by observations (Talone et al. 2009, 2011). The resulting 

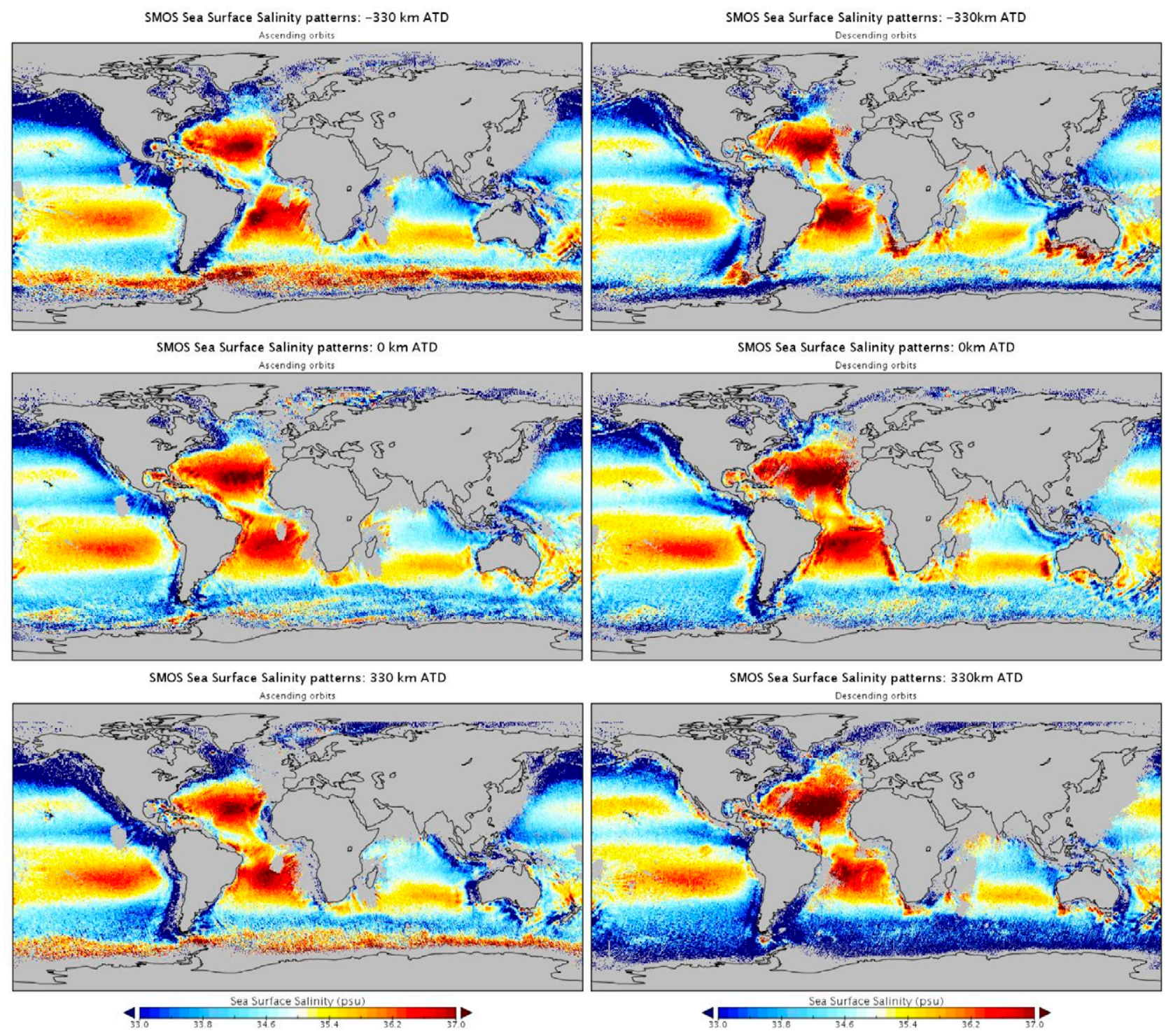

Fig. 5. - SMOS average salinity maps depending on the across-track distance or distance from the grid point to the centre of the swath.

algorithms were tested with airborne L-band measurements acquired in field campaigns (Talone et al. 2010, Gabarró et al. 2008).

Currently, the BEC team is investigating statistical methods for salinity retrieval that could go further than present schemes and at the same time diminish the impact of some observed biases. The aim of these new approaches is to simplify the cost function as much as possible, increasing the number of retrievals at the cost of enlarging the error on each individual retrieval. To this end, each TB acquisition is processed separately so that each one provides a value of SSS; to make this feasible, all the parameters defining the forward model except SSS are fixed. In particular, for each SMOS measurement, the function to be optimized is

$$
f(S S S)=\left(T_{B}^{\text {meas }}(\theta)-T_{B}^{\text {mod }}(\theta ; S S S, S S T, w)\right)^{2}
$$

To simplify the problem, the brightness temperatures in the above formula correspond to the first
Stokes parameter measured at the bottom of the atmosphere. Then, for every geolocated point not only a single salinity is retrieved with each satellite pass, but a set of them, distributed according to a common distribution, so the statistics can be analysed to find the most representative salinity. This approach allows the implementation of non-linear methods (for instance, the analysis of the mode or median filters) that can diminish the impact of outliers. To enlarge the statistics and hence improve the quality of the retrieved salinity, we accumulate the statistics of all the grid points that fall in a spatial grid (typically sampled at a spatial resolution of $0.25^{\circ} \times 0.25^{\circ}$ ) during a given temporal range (typically 9 days). Hence, we estimate the distributions of salinities, with all the associated statistical information (such as the mean, the median, the mode, the standard deviation, the skewness and the kurtosis) for all the points in the map. We are presently analysing all these statistical descriptors to find out which ones are the most appropriate and robust for the generation of salinity maps. 

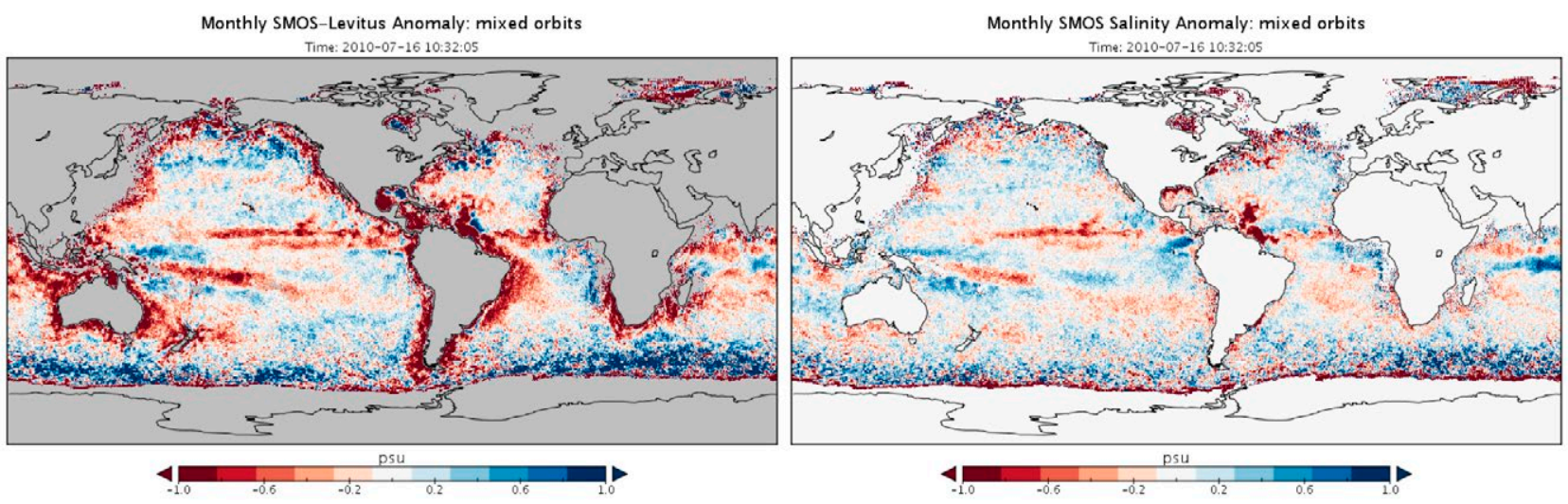

Fig. 6. - SMOS salinity anomalies in a monthly map (July 2010). Left, SMOS anomalies computed with respect to Levitus climatology. Right, SMOS salinity anomalies with respect to SMOS climatologies (separated by direction overpass and ATD (Across-Track Distance)).

\section{L3 ACTIVITIES}

\section{Sea surface salinity}

\section{SMOS anomalies}

The salinities provided by ESA, the Level 2 Ocean Salinity User Data Product and the Ocean Salinity Data Analysis Product are filtered and processed at BEC. Due to the complexity of the instrument, there are still many error patterns that are not completely understood (as discussed in the previous sections regarding L1 and L2 processing). Fortunately, after almost 6 years of mission a large data set is available, and all that information can be used for modelling these patterns. Figure 5 provides information about the patterns that can be found in salinity maps. The salinities of 4 years with the same geolocalization (latitude and longitude), the same orientation of the overpass (ascending or descending) and the same position with respect to the centre of the satellite swath (across-track distance (ATD), which is negative for points to the left of the centre and positive for points to the right), were averaged. The averaging of the retrieved salinities according to the above criteria is performed because land-sea contamination depends on the position of the coast in the antenna and its orientation. Many artefacts are evident from the inspection of Figure 5, especially near

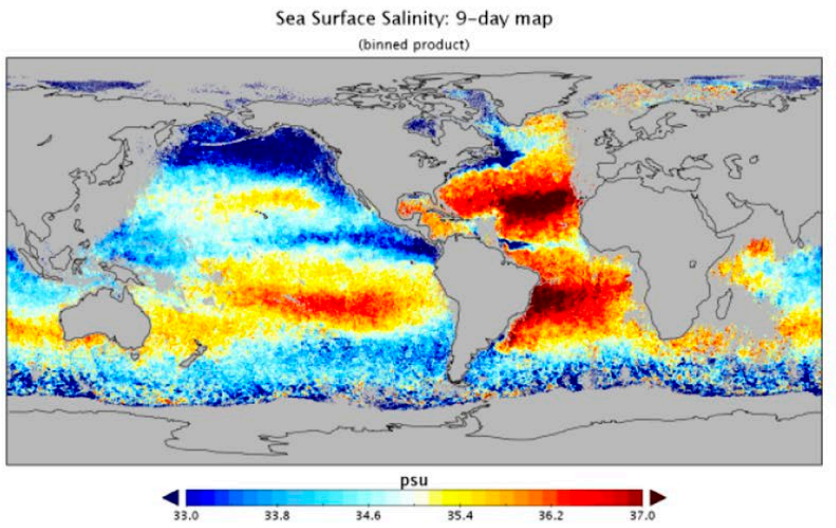

to the coast. For instance, close to the Brazilian coast, the average salinity may be lower than 33 psu but also higher than $37 \mathrm{psu}$, depending just on the direction of the satellite overpass and on the ATD of the measure. These climatology-like maps of SMOS salinities can be subtracted from each Level 2 salinity value, leading to SMOS anomaly maps where land-sea contamination is much lowered (see Fig. 6). Absolute values of salinity can be derived from the SMOS anomaly maps by adding a reference salinity field.

\section{Weighted average and objective analysis}

Moreover, BEC has the capacity of generating added-value products. Weighted average maps are generated from L2 salinities accumulated with a given weight for a few days in a fixed spatial grid. The map on the left of Figure 7 is an example of this kind of binned map with a spatial resolution of $0.25^{\circ} \times 0.25^{\circ}$ and a temporal resolution of 9 days. Typically, these maps are very noisy and contain many gaps. For this reason, the application of algorithms for reducing noise and extrapolating salinities becomes useful. BEC has studied and analysed the performance of two different algorithms: optimal interpolation and objective analysis. The map on Figure 7, right, was computed with the same L2 salinities as the one on the left, but using objective analysis.

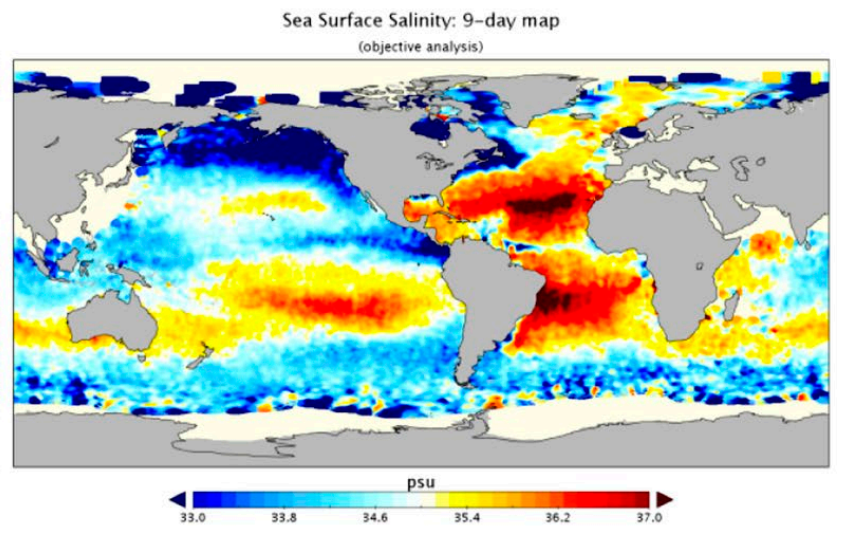

Fig. 7. - Sea Surface Salinity maps with spatial resolution of $0.25^{\circ} \times 0.25^{\circ}$ and temporal resolution of 9 days. Left, map computed by averaging the properly filtered L2 (Level 2) salinities. Right, objective analysis was used for the processing of the filtered salinities. 
Binned SSS maps are constructed by the weighting average of Level 2 SSS retrievals, i.e., , that lie inside the -th bin:

$$
\operatorname{SSS}_{I}^{L 3}=\frac{\sum_{i \in I} w_{i} S S S_{i}^{L 2}}{\sum_{i \in I} w_{i}} \text {, with } w_{i}=\left(R_{i}^{2} \sigma_{i}^{2}\right)^{-1} .
$$

The weight $w_{i}$ is inversely proportional to the theoretical uncertainty of the L2 retrieval, $\sigma_{i}$, and to the equivalent footprint size associated with each retrieval, which depends on their position on the image. Therefore, the weight is only a function of each L2 observation being averaged. Weighted average products are operationally produced at BEC and distributed via its webpage.

\section{Optimal interpolation (OI)}

In order to increase the geophysical consistence of the salinity maps, to reduce noise and to fill data gaps that might exist when generating Level 3 salinity maps, Level 2 SSS maps are optimally interpolated (see Bretherton et al. 1976), according to the following formula:

$$
S S S_{I}^{O I}=\operatorname{SSS}_{I}^{B}+K_{l j}\left(S S S_{j}^{L 3}-\operatorname{SSS}_{j}^{B}\right) .
$$

In this equation, the weight $K_{I j}$ is a vector whose components depend on the error covariances of a background field, $S S S^{B}$, and of the Level 3 salinity values used as observations. The background field should provide a plausible value of the salinity field in the absence of observations. In our case, the background field is the surface $(0 \mathrm{~m})$ salinity field of the 2009 WOA climatology (Antonov 2010). The set of observations $\operatorname{SSS}_{j}^{L 3}$ comes from a region within about $660 \mathrm{~km}$ (at the equator) from the analysis point $\operatorname{SSS}_{I}^{O I}$. The influence distance is reduced with the cosine of the latitude. Observations are also required to belong to the same ocean basin to avoid interpolation across continental barriers.

The weight matrix $K_{I j}$ is a function of the location of the interpolation point and of the location of the $j \in J$ observations. According to Bretherton et al. (1976),

$$
K_{l j}=B_{I k}(\mathbf{B}+\mathrm{R})_{k j}^{-1}
$$

where $\mathbf{B}$ is the background error covariance matrix that accounts for the spatial decorrelation of the background error between each pair of observation inside the region of influence. Following Jordà and Gomis (2009), the background error covariance function is given by:

$$
\begin{aligned}
B_{k j}=B_{o} \exp \left\{-\left[a_{k}\left(x_{k}-x_{j}\right)^{2}+b_{k}\left(y_{k}-y_{j}\right)^{2}+\right.\right. \\
\left.\left.+c_{k}\left(x_{k}-x_{j}\right)\left(y_{k}-y_{j}\right)\right]\right\}
\end{aligned}
$$

The coefficient $B_{o}$, which denotes the variance of the background field error, depends on the particular background field. At BEC, the error variance of the WOA09 surface salinity field has been set to $0.3^{2}$ to ensure the stability of the inversion algorithm. The observational error variance matrix, $\mathrm{R}$, is supposed to be diagonal (assuming that the error in each L3 bin is independent of the error of the other bins) and equal to the dispersion of the L2 salinity retrievals inside each bin. Bins whose dispersion exceeds a given value (fixed at 10) are disregarded. These OI products are operationally produced at BEC and distributed via its webpage.

\section{Validation of SSS products}

Although there are several components of the global ocean observing system that provide systematic observations of the salinity near the surface (e.g. moored buoys, Argo, surface drifting buoys, ships of opportunity, etc.), Argo remains the only global, allweather, all-season observing component providing a quasi-uniform, real-time set of ocean salinity observations (http://www.argo.ucsd.edu). At BEC, the systematic validation of SSS products is done with Argo data.

The Argo data used to validate the various SSS products are selected as follows:

- Delayed-mode and real-time data are used (the impact of using real-time data is discussed below).

- For each profile, only primary current, temperature and depth measurements are used.

- Only data (pressure, temperature and salinity) with the highest quality control value $(\mathrm{QC}=1)$ are used. See the quality control flag value and meaning in Table 2 of $\operatorname{Argo}(2013)$.

- The quality control of geographical position and date position is accepted if it has been set to 1 (good), 2 (probably good), 5 (Value changed) or 8 (Interpolated value).

- The uppermost valid salinity measurement is taken, without accepting any salinity value closer than $0.5 \mathrm{~m}$ to the surface. Some authors have observed erroneous measurements likely due to inaccuracies in the pressure measurement (Boutin et al. 2012).

Salinity data from PROVOR, SOLO (as well as UNKNOWN) instruments are not considered at depths shallower than $5 \mathrm{~m}$, as these profiler types do not pump water at a depth shallower than $5 \mathrm{~m}$ (Argo 2013).

The number of available profiles in the period 2011-2013 is shown in Figure 8. The plot also displays the number of available surface observations according to the depth of the uppermost salinity and temperature observations. While more than 4000 observations are available monthly in the upper $5 \mathrm{~m}$, less than 1000 salinity observations are available in the first three metres. Validation of SMOS SSS products will be limited to those SMOS/Argo matchups where the uppermost salinity measurement is no deeper than $10 \mathrm{~m}$.

As will be discussed below, the main advantage of using delayed-mode Argo salinity data lies in the filtering of wrong data rather than in the value of the adjusted salinity correction. Therefore, when real-time profiles are used, additional selection rules are used to remove suspicious data. In particular, surface Argo salinity values are compared with WOA 2013 surface fields, and the Argo data will be removed if the difference against WOA 13 is larger than 5 . 


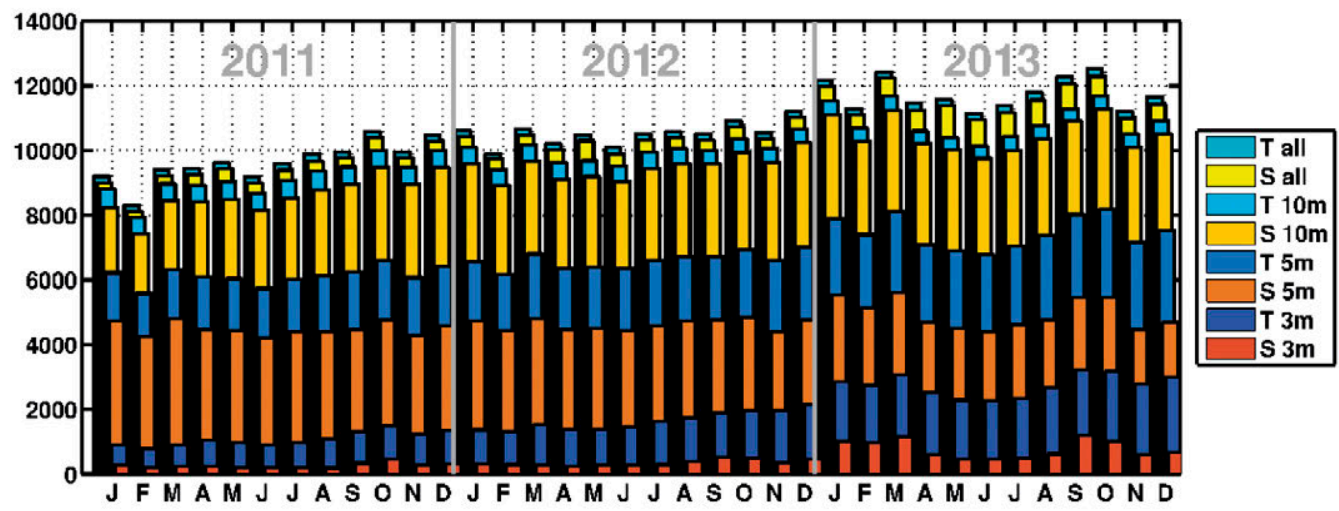

Fig. 8. - Number of Argo profiles per month during the period January 2011 to December 2013. The number of data available at 3, 5 and 10 $\mathrm{m}$ is also shown.
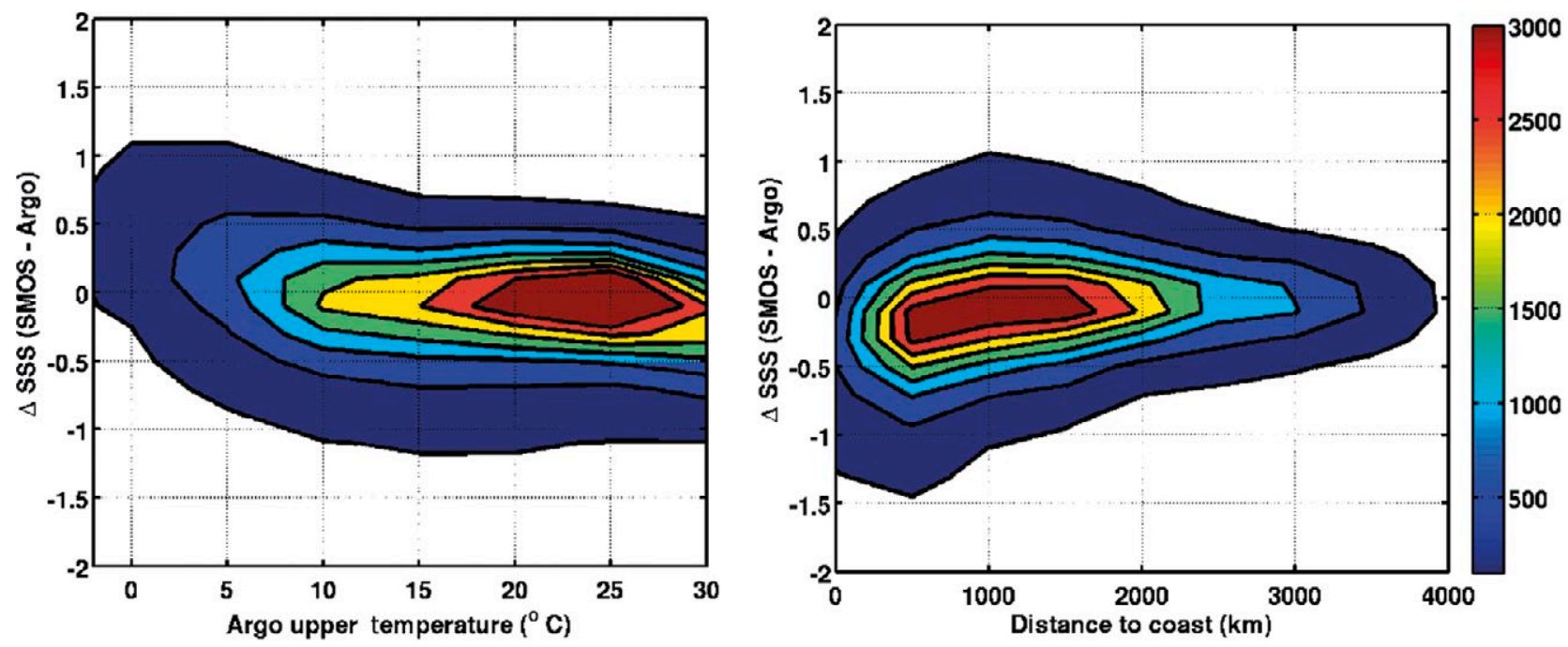

Fig. 9. - Bidimensional histogram of the salinity difference between SMOS and Argo as a function of the uppermost temperature measured by Argo (left) and as a function of the distance to the coast (right). These plots have been created using only Delayed Mode Argo profiles. Colour indicates the number of SMOS/Argo matchups.

Evaluation of the performance of the SMOS mission to retrieve SSS has to take into account that the sensitivity of the brightness temperature to salinity diminishes as water temperature falls. Figure 9, left, shows that a bias between satellite and in situ appears for water temperatures below $5^{\circ} \mathrm{C}$. Similarly, current DPGS (Data Processing Ground Segment) algorithms are affected by strong land-sea contrast and the presence of RFI. Both effects combine to increase the bias of the difference between the satellite and the in situ temperature near the coast. Henceforth, SMOS/Argo matchups will be limited to those for which the surface temperature is greater than $5^{\circ} \mathrm{C}$ and located farther than $1000 \mathrm{~km}$ from the coast.

Table 1 displays the statistics of the differences between the 9-day, 0.25-degree SMOS products and the Argo surface. Notice that the error is reduced with increasing processing level, demonstrating the denoising capabilities of both OI and a data fusion technique developed by BEC (see the section on L4 activities below, where this data fusion technique is explained in detail). According to Table 1, the expected accuracy of the BEC SSS products is about 0.3.

It must be expected that the estimate of error shown in Table 1 contains both random and representative error. The source of the representative error mainly arises from the differences in the nature of the SMOS and the Argo measurements. First, the SMOS measures represent area averages of about $25-50 \mathrm{~km}$ and time averages of 9 days. The in situ data represent instantaneous (less than one minute) point measurements. On the other hand, SMOS is measuring the emissivity of the first $\mathrm{cm}$ of the ocean surface, while Argo measurements are taken no closer than half a metre from the

Table 1. - Statistics of the differences between the 9-day, 0.25-degree SMOS products and the Argo surface.

\begin{tabular}{ccccccccc}
\hline & $n$ & $\min$ & $\max$ & ave & med & Std dev & IQR & RMS \\
\hline L3 & 128536 & -5.47 & 7.38 & -0.05 & -0.05 & 0.49 & 0.54 & 0.49 \\
OI & 134754 & -4.40 & 4.10 & -0.05 & -0.05 & 0.30 & 0.34 & 0.31 \\
L4 & 128536 & -4.43 & 3.93 & -0.10 & -0.11 & 0.30 & 0.36 & 0.31 \\
\hline
\end{tabular}



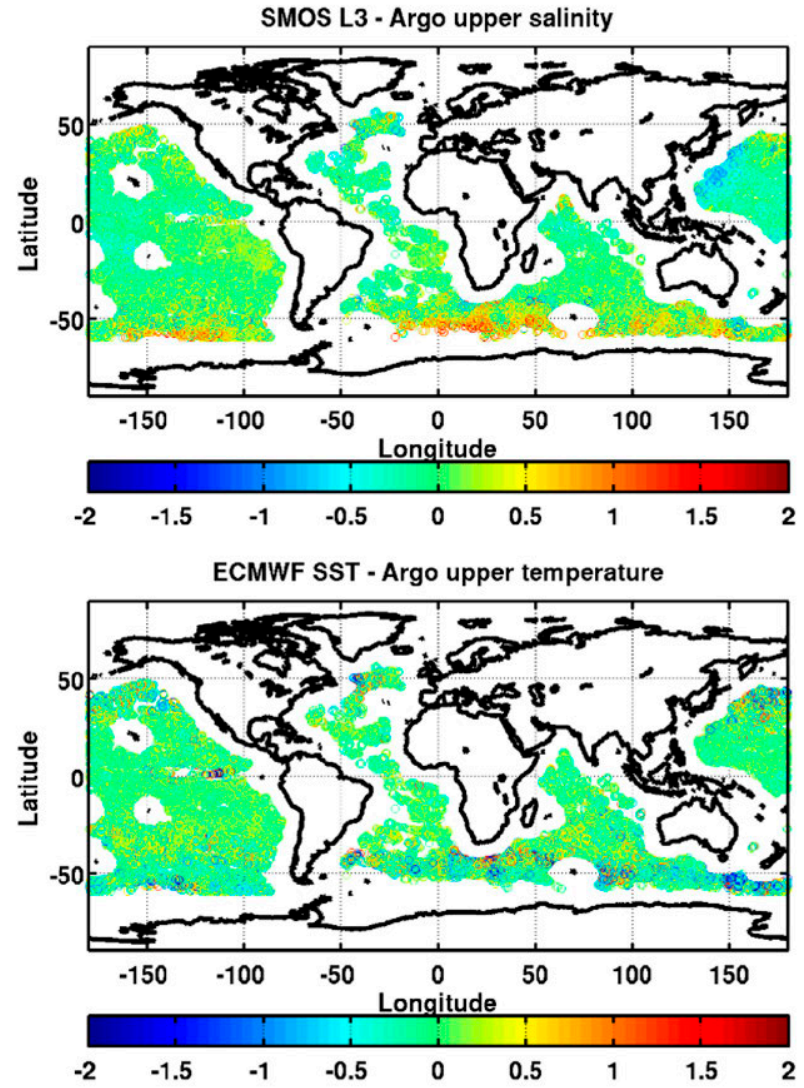

Fig. 10. - Spatial distribution of the differences between SMOS and Argo surface value (top) and spatial distribution of the differences between OSTIA SST and the Argo upper temperature (bottom).

surface. Although sophisticated tools are available to infer representativeness errors by considering different sources of information (see, for example, Stoffelen (1998)), a cursory estimate of the lower bound of the representativeness error can be obtained with the help of the temperature field. For example, Figure $10 \mathrm{com}-$ pares the difference of the SMOS OI SSS and the Argo SSS (top) and the difference between OSTIA SST and the Argo SST for the same matchup locations. Notice that the two maps show some common patterns. These patterns are located mainly in regions of strong fronts, as is illustrated by regions with a strong representativeness error. The number of points with temperature differences larger than $0.3^{\circ} \mathrm{C}$ is more than 47,000 . The standard deviation of these matchups is 0.33 (compared with the overall 0.30). Similarly, if the matchups with large temperature differences are removed, the standard deviation of the differences between SMOS and Argo is reduced from 0.30 to 0.28 . As a consequence, a lower bound of the representative error due to spatial variability is about 0.2 , an order of magnitude smaller than the difference between SMOS and Argo.

As new improvements are incorporated into the operational chain, reprocessing campaigns are performed by ESA. BEC creates new salinity global maps from these data and exhaustive quality control reports are made. These quality reports are published on the BEC-CP34 (http://cp34-bec.cmima.csic.es/) webpage as soon as new maps are provided.
Sea ice

Although sea ice was not considered as a leading objective for SMOS, the Sea Ice scientific community realized that interesting results could be obtained from SMOS data, since its low microwave frequency allows a certain penetration in ice. Kaleschke et al. (2010) theoretically showed that SMOS could measure ice thickness of thin ice, up to 50-60 cm depending on the salinity and the temperature of the ice. Kaleschke et al. (2012) and Huntemann et al. (2013) showed the first ice thickness results with real data, demonstrating that the L-band is a very promising band for cryospheric studies. The University of Hamburg is now providing near real-time SMOS ice thickness maps for the period November to April every year.

In Gabarró et al. (2015) it was shown that sea ice concentration (SIC) could also be estimated with SMOS data. The polarization difference and angular difference indices were selected to properly distinguish between sea and ice. These indices are less dependent on the geophysical parameters (temperature and salinity of the ice) than the raw brightness temperature, while their values in the two different phases are different enough for a proper classification. The classification is based on two tie points, which correspond to $100 \%$ ice and $100 \%$ sea, similarly to other algorithms (Comiso et al. 2003). An analysis of the temporal stability of the tie points was performed, showing very stable values. A linear combination of both tie points allows SIC to be estimated at a given geographical pixel. However, due to its ice penetration, pixels with a significant presence of thin ice are classified as partially covered even if the pixel is totally covered by ice, since the brightness temperature (and the indices) in the thin ice regions (less than $60 \mathrm{~cm}$ ) is lower than for thick ice, which is the ice used to define the $100 \%$ ice tie point. SMOS-derived SIC has been compared with the results of the ASI algorithm for ice concentration derived from AMSR2. The ASI algorithm (Kaleschke et al. 2001) uses the $89 \mathrm{GHz}$ frequency band, which has a very low penetration in ice. Therefore, most of the differences between the two sensors are due to the thin ice, which is observed differently. Figure 11 shows SMOS-derived SIC, AMSR2-derived SIC with the ASI algorithm, and the difference between the two on 3 days of November, 2014, when maximum thin ice is present. Further work is now being carried out at BEC to improve our SMOS SIC algorithm; we are also working on a different algorithm to retrieve ice thickness from SMOS data.

Another significant contribution of SMOS to the study of the cryosphere is iceberg tracking (Slominska et al. 2015), precisely taking advantage of the strong contrast between sea and ice, especially for a relatively small piece of ice surrounded by sea.

\section{Soil moisture}

The Level 3 SM product is generated from the operational ESA Level 2 SM User Data Product that includes geophysical parameters, a theoretical esti- 


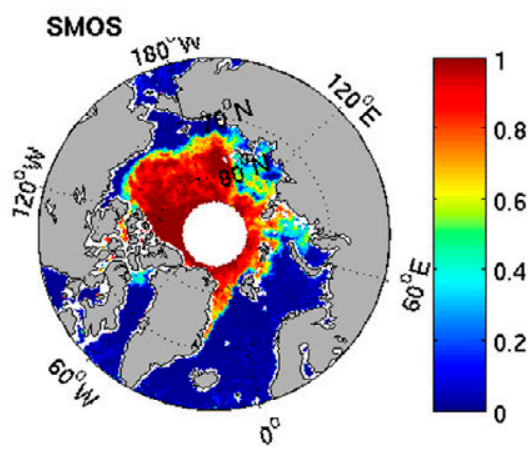

Ice concentration

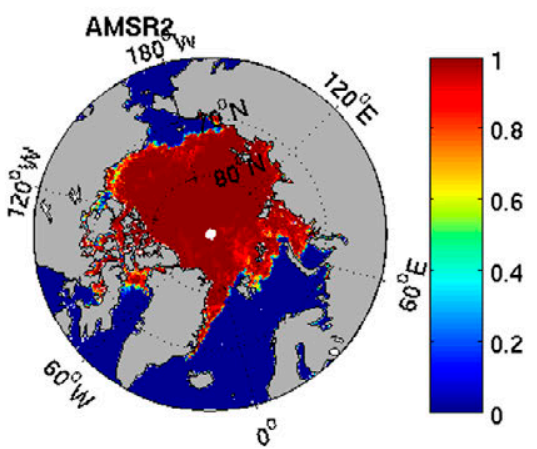

Ice concentration

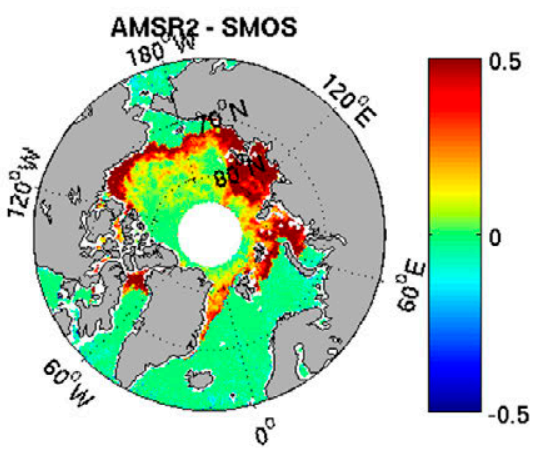

Ice concentration

Fig. 11. - Sea ice thickness measured by SMOS from 2 to 5 Nov. 2014 (top left), measured by AMSR2 on 3 Nov. 2014 with ASI algorithm (top right) and the differences between them (bottom).

mate of their accuracy, and a set of product flags and descriptors.

The nominal L2 SM data is first filtered in order to ensure the quality of our L3 products. SM values are rejected if: i) no value has been retrieved for that given grid point; ii) the retrieval is negative; iii) the retrieval is outside the extended range; or iv) the associated data quality index is larger than $0.07 \mathrm{~m}^{3} / \mathrm{m}^{3}$. Next, a weighted average is performed to bin the data to an EASE-ML grid with cells of $25 \mathrm{~km}$. Products are provided in netCDF format and in a variety of temporal and spatial resolutions. A comprehensive evaluation of these products using two complementary small-scale and large-scale in situ networks and a surface water balance model was performed in González-Zamora et al. (2015). The results showed that BEC L3 SM estimates are consistent with in situ measurements in the time-series comparisons, with Pearson correlation coefficients $(\mathrm{R})$ and an agreement index higher than 0.8 for the total average and the land-use averages and higher than 0.85 for the soil texture averages.

\section{L4 ACTIVITIES}

\section{Sea surface salinity maps}

More sophisticated algorithms have also been developed at BEC with the aim of decreasing the noise and increasing the spatial information of the binned maps. Umbert et al. (2014) presented a new algorithm to blend information coming from different ocean variables using their common multifractal structure. This algorithm is currently being used at BEC for the operational generation of L4 SSS maps. SST maps provided by OSTIA are employed as template variables to diminish the impact of noise on SMOS SSS maps. The idea of the method is based on the assumption that the singularity exponents of SST and SSS are the same (the theoretical basis and the empirical evidences of this correspondence are shown in Umbert (2014)). A discussion on singularity exponents and their meaning can be found later on in this same work.

By using this synergy between SSS and SST, we can obtain maps in which the dynamics of the salinity is restored and thus some processes can be studied in detail. Figure 12 shows an example of the application of the algorithm in the equatorial Atlantic $\left(-20^{\circ}\right.$ to $20^{\circ}$ latitude). The 9-day maps are calculated every 3 days, starting on 26 June 2012. The evolution of the Amazon plume as well as the plume of several African rivers (the Niger and Volta) is shown; in the image it can be clearly seen that the fresher, less dense water occupies a vast majority of the surface in the equatorial Atlantic as the season progresses.

\section{Sea surface density}

A new product of surface density based on the new equation of state for sea water has been obtained: the Thermodynamic Equation of Seawater - 2010 (TEOS10). TEOS-10 is based on a Gibbs function formulation from which all thermodynamic properties of seawater (density, enthalpy, entropy sound speed, etc.) can be derived in a thermodynamically consistent manner. The product is under validation for an imminent product release. So far, the maps are based on the combination of OI SSS L3 and OSTIA SST (see Fig. 13), and the validation against Argo gives an estimated error of $0.30 \mathrm{~kg} \mathrm{~m}^{-3}$, which is still considerable although well in line with the expectations. Future developments include the introduction of algorithms to reduce the error and to study some important derived quantities (e.g. density fluxes).

\section{Singularity exponents derived from OSTIA SST}

One of the noteworthy features observed when studying ocean variables of different types, with different equations governing their evolution, is the pervading presence of some recognizable ocean structures in all of them. The underlying reason for the consistent structural appearance of all ocean scalars is the existence of an advection term in all evolution equations. The advection term is not necessarily the dominant one, but it is strongly non-linear, and it induces sharp transitions associated with the places where flow shear is large. Mathematically, a sharp transition in a scalar can be characterized by a negative singular exponent of its gradient. The singularity exponent (Turiel et al. 2008) is a dimensionless variable that characterizes the 

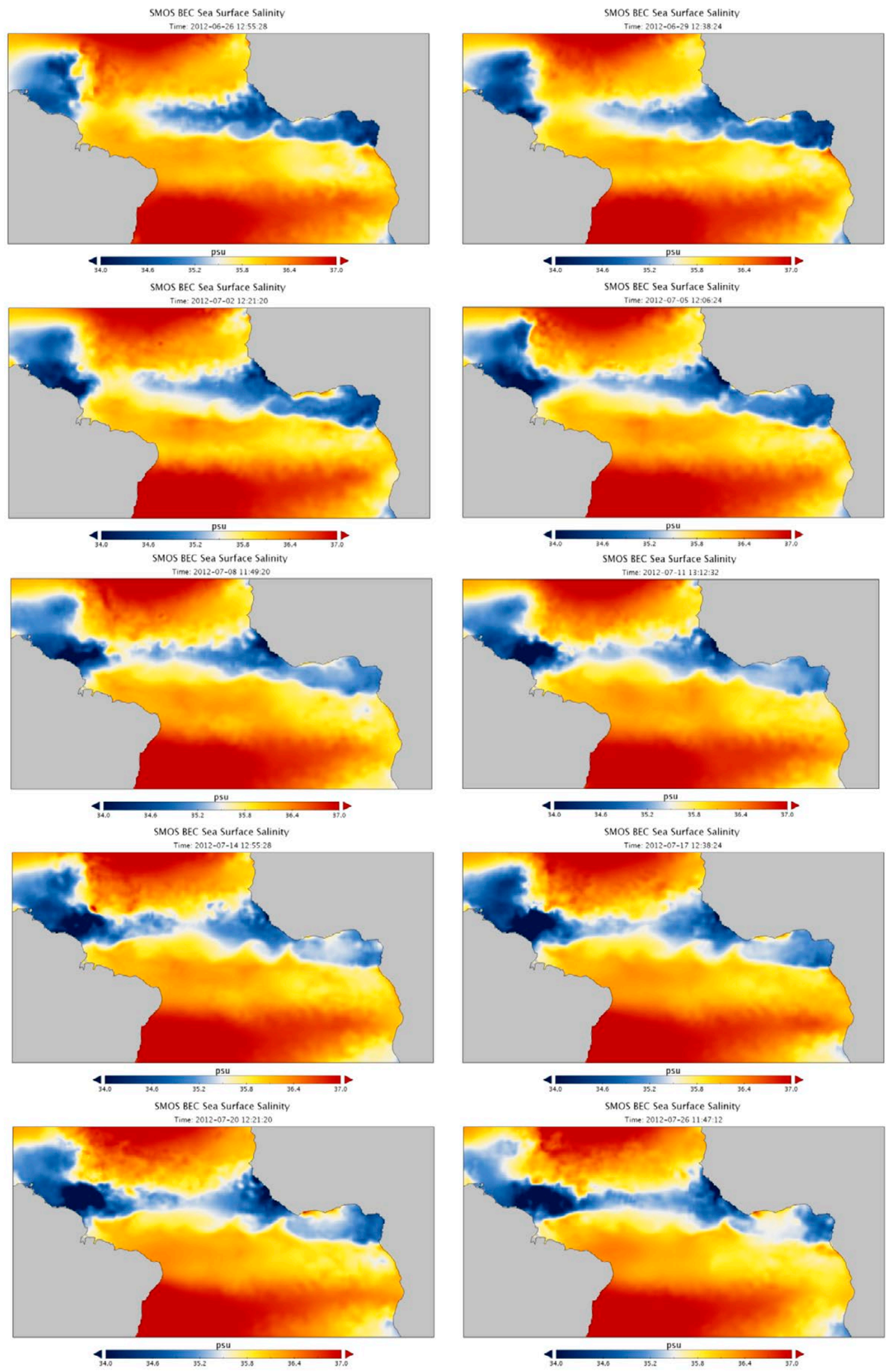

Fig. 12. - SMOS view of the salinity variability in the Tropical Atlantic Ocean. 


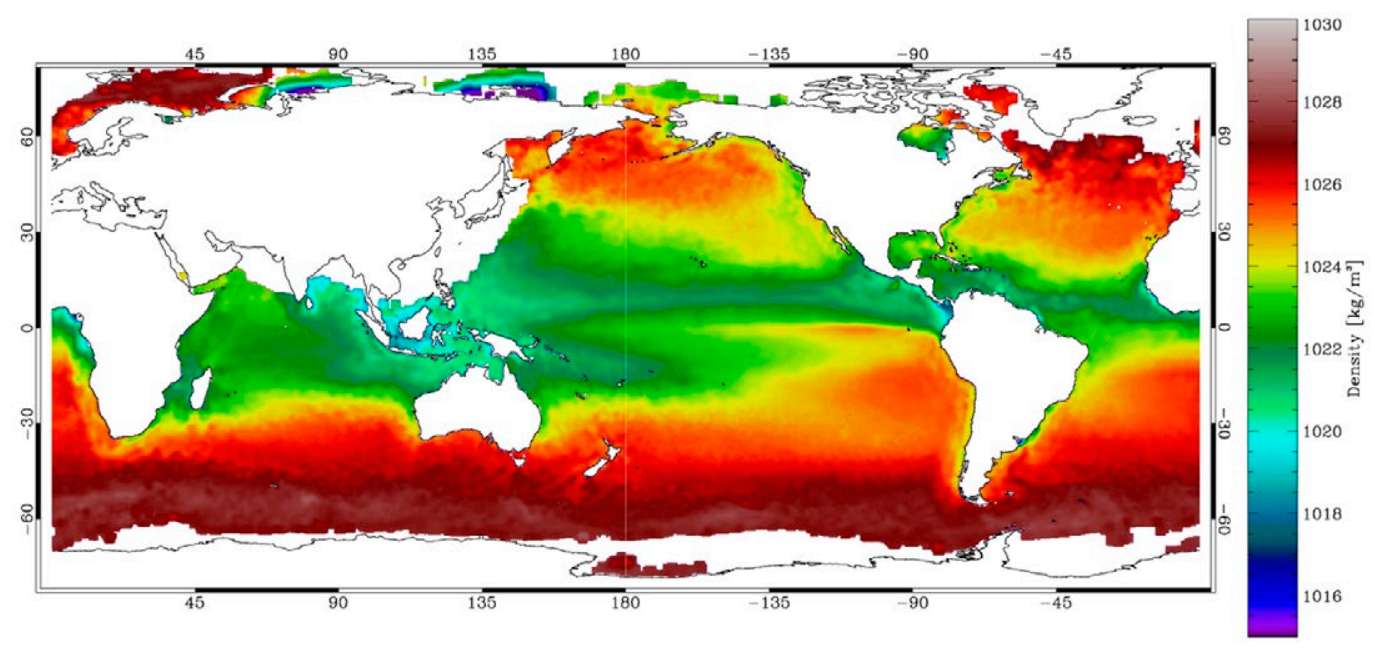

Fig. 13. - Map of average surface densities at global scale, derived from SMOS OI data and OSTIA SST, for the period January-March 2010.

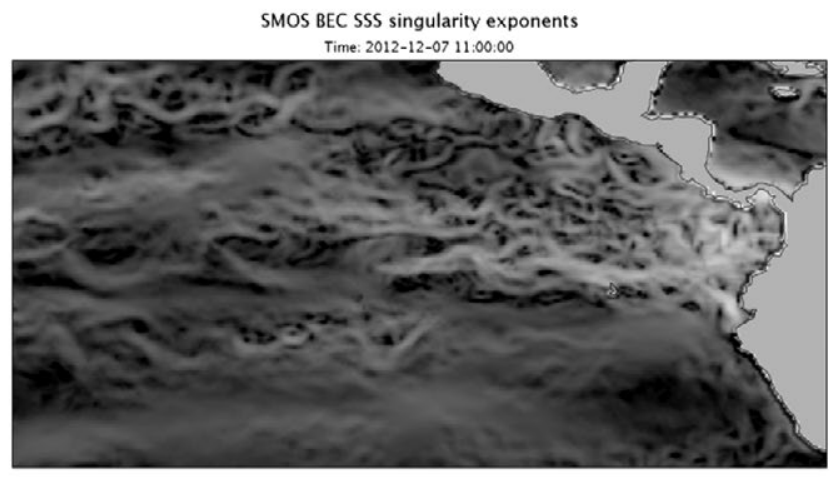

SMOS BEC SSS singularity exponents

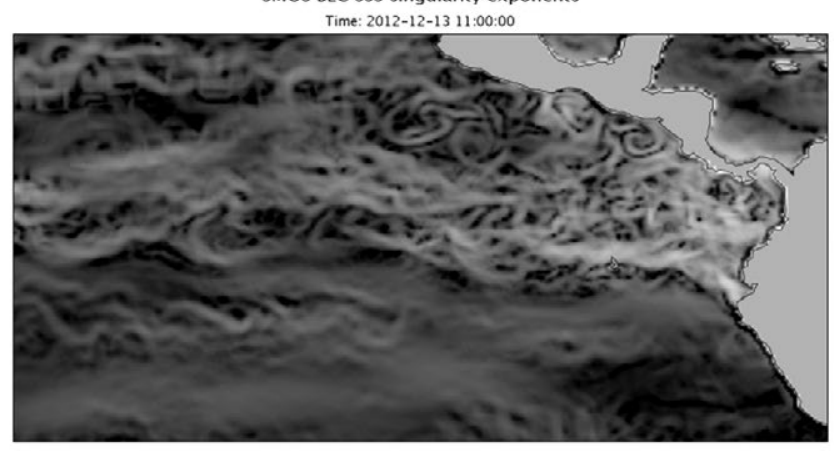

\begin{tabular}{l}
$\triangleleft$ \\
\hline
\end{tabular}

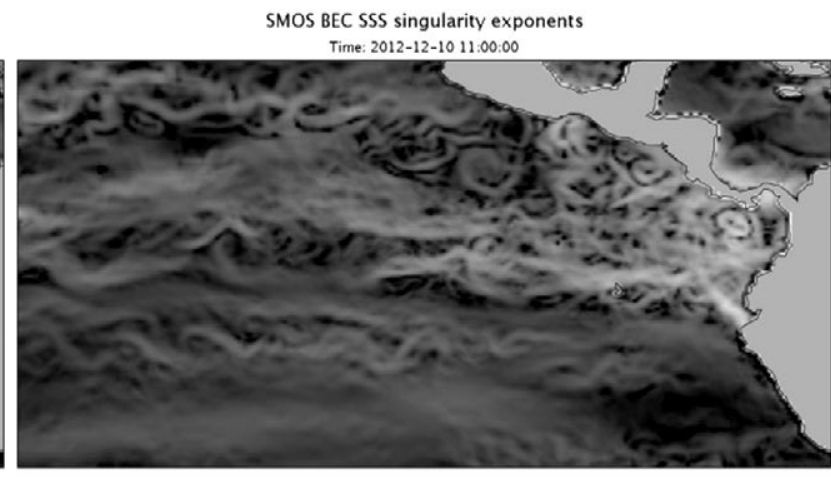

SMOS BEC SSS singularity exponents

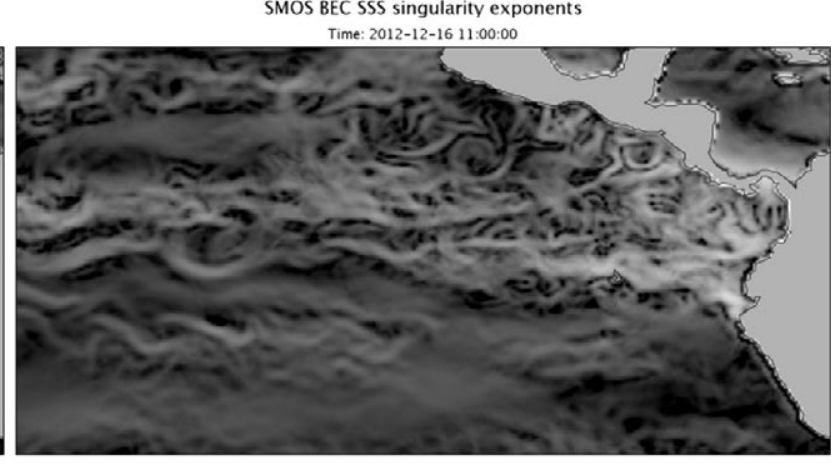

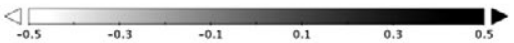

Fig. 14. - Singularity exponents of four 9-day L4 salinity maps in the equatorial Pacific. The plots show the evolution of rings close to the Gulf of Panama.

sharpness or regularity of the spatial variation of a scalar around each point, and thus singularity exponents coming from different variables can directly be compared. Furthermore, they are directly associated with the streamlines of the flow (Turiel et al. 2008). Hence, obtaining the singularity exponents of any scalar (a process generically known as singularity analysis) allows characterizing the structure of the underlying flow and provides relevant dynamic information. See, for instance, Figure 14; we can observe the creation (second map in the sequence) and destruction (third map) of a ring close to the Gulf of Panama (in the examples presented, singularity exponents were calculated from L4 9-days salinity maps).
BEC has made an effort to make the information obtained from singularity analysis available to any interested user, in a two-fold strategy. First, high-quality maps of singularity exponents derived from daily SST OSTIA maps at a coarsened spatial resolution of 0.25 degrees are being distributed. SST is presently a high-quality variable and the OSTIA standard allows streamlines with singularity exponents of unprecedented quality to be tracked; singularity maps are served in the standard netCDF format to ease numerical processing of the results.

In addition to the distribution of these high-quality singularity maps, a graphical user interface allows the user to upload any netCDF file containing a geophysi- 
cal variable of interest that will be processed by our web system. The resulting singularity exponents will be displayed on the screen, and could be downloaded in netCDF format for later use. This allows the user to process data not only from SMOS or OSTIA, but from any source: remote sensing, in situ or numerical simulations. The interface could even be used for processing non-oceanic variables (although in that case the geophysical interpretation is less straightforward). The service may be accessed at http://cp34-bec.cmima.csic. es/CP34GUIWeb/ upon registration (which is free).

\section{High-resolution soil moisture products}

Due to practical constraints on antenna size and altitude of low Earth orbits, the spatial resolution of spaceborne L-band radiometers is currently limited to 40 $\mathrm{km}$. An innovative microwave/optical downscaling approach was developed to combine SMOS observations with NASA's MODIS visible/infrared complementary data into high spatial resolution $(<1 \mathrm{~km})$ soil moisture fields. The core of the algorithm is an empirical model that links microwave/optical sensitivity to SM and linearly relates the two instruments across spatial scales (Piles et al. 2011, Sánchez-Ruiz et al. 2014, Piles et al. 2014). Knowledge of SM at these scales is important for numerous applications, including water resource management, agricultural productivity estimation, ecological modelling and fast reaction to natural hazards (e.g. floods, forest fires, landslides). This downscaling scheme is operationally implemented at SMOS-BEC facilities to provide fine-scale soil moisture maps over the Iberian Peninsula, available from 2010 to the present (http://cp34-bec.cmima.csic.es). Since 2012, two near real-time $(<12 \mathrm{~h}$ delay from every SMOS overpass) soil moisture maps are daily generated to meet the needs of early-warning and meteorological systems (Piles et al. 2013). Near real-time capabilities are possible thanks to collaboration with LATUV, Valladolid University, which receives and processes every overpass of MODIS data over the Iberian Peninsula.

The downscaling approach adopted by BEC was first presented in Piles et al. (2011), along with results of its application to a set of SMOS images acquired during the commissioning phase over the Oznet network, South-East Australia. Using reprocessed SMOS data obtained with improved L1 and L2 processors, further development and validation of this technique have re- sulted in a fine-tuned and more robust methodology for SM estimation at high spatial resolution, which benefits from SMOS polarimetric and multi-angular information (Sánchez-Ruiz et al. 2014a, Piles et al. 2014). This is the current version of the algorithm implemented at BEC facilities to produce the L4 SM product.

Piles et al. (2014) evaluate the temporal and spatial variability of two years of BEC fine-scale $(1 \mathrm{~km}) \mathrm{SM}$ estimates over the Iberian Peninsula through comparison with ground-based measurements acquired at the in situ SM measurement network (REMEDHUS) located in the central part of the Duero basin, Spain. The results show that the downscaling method improves the spatial representation of SMOS coarse soil moisture estimates (SMOS L2) while maintaining temporal correlation and root mean-squared differences with ground-based measurements. Figure 15 shows the temporal evolution of SM time series (i.e. SMOS L2, SMOS-BEC L4, in situ) over REMEDHUS. Note that areal-averaged downscaled estimates match well with in situ data (circles are enclosed within the network's SM variability in shaded green). Scatter plots of Figure 16 display the agreement between remotely sensed SM and REMEDHUS in situ time series, with segments illustrating the linear fit of seasonal data. Comparisons between SMOS L2 and in situ point-scale measurements (left column), and between 1-km soil moisture and in situ point-scale measurements (right column) are shown for a representative station of rainfed cereals, the most common land-use in the area, with intermediate water content. It can be seen that the slope of the linear correlation is significantly improved in the L4 maps (close to the 1:1 line) and the dynamic range of in situ SM measurements is reproduced in the highresolution maps, including stations with different mean soil wetness conditions (see further results in Piles et al. (2014)). This evaluation study supports the use of this downscaling approach to enhance the spatial resolution of SMOS observations over semi-arid regions such as the Iberian Peninsula. The synergy of L-band microwave and optical data for high-resolution SM mapping has also been validated using airborne observations (Sánchez et al. 2014, 2015).

High-resolution SM maps in NRT are being routinely used by the Barcelona Provincial Council (DiBa) for fire risk assessment and prevention during the forest fire season (June-September). Since June 2012, SMOS-derived fine-scale soil moisture information is being included in

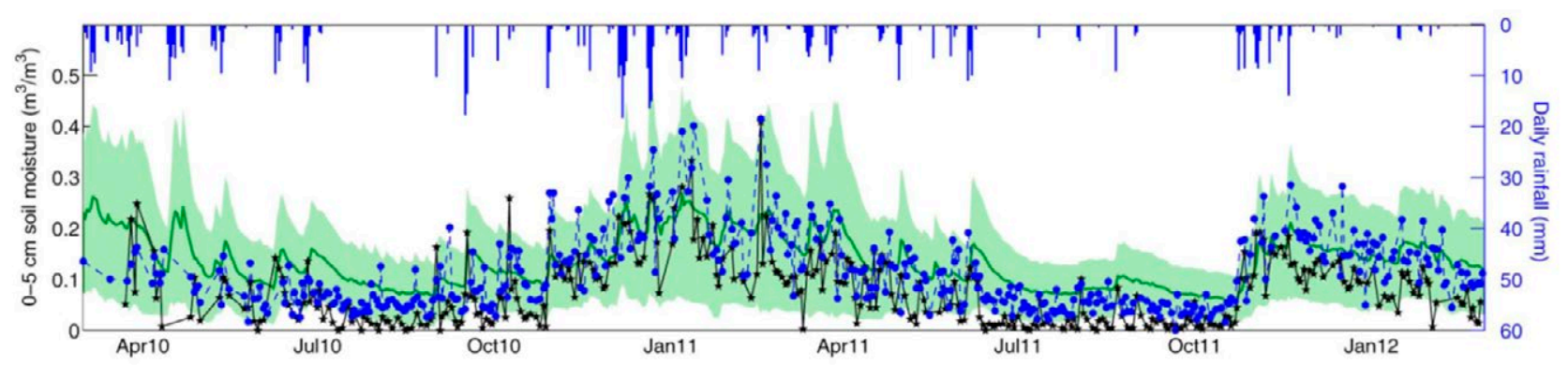

Fig. 15. - Temporal evolution of surface soil moisture time series over REMEDHUS: ground-based mean (green solid line) and standard deviation (green shaded areas), SMOS L2 (black stars), 40-km aggregated SMOS/MODIS downscaled (blue circles). Daily mean rainfall on top (from Piles et al. 2014a). 

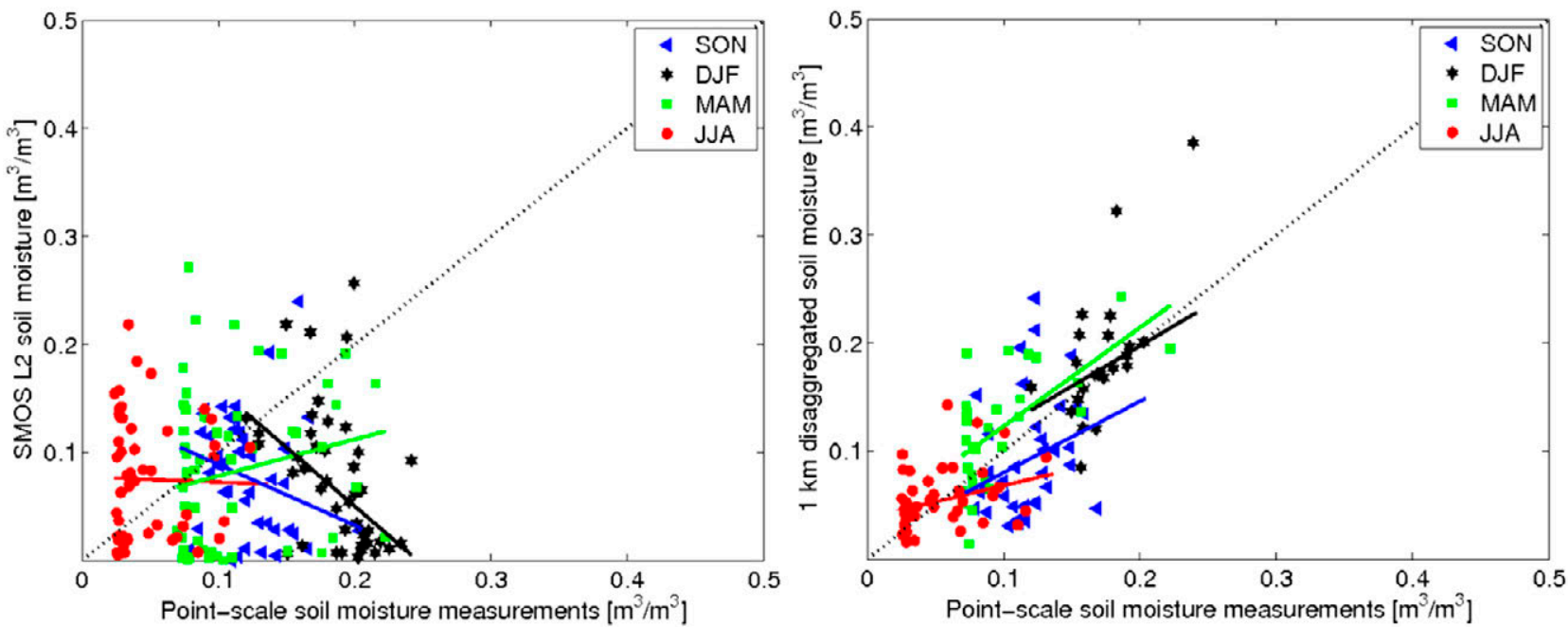

Fig. 16. - Results of the seasonal analysis for the hydrological year starting in September 2010 (afternoon passes) over station 07 (rainfed cereals). Left, scatter plot of SMOS L2 soil moisture versus point-scale measurements. Right, scatter plot of 1-km SMOS-MODIS disaggregated soil moisture versus point-scale measurements. Segments are linear fit of seasonal (3-month) data (from Piles et al. 2014a).

DiBa's fire risk prevention service daily bulletin with the purpose of detecting areas with extreme dryness posing a risk of forest fire. This daily bulletin is used by DiBa to decide where to deploy the forest fire prevention agents within the Barcelona province. With five years of data, it is now possible to detect SM anomalies leading to spring and autumn fires. Chaparro et al. (2015) report a relationship between SM, land surface temperature and burned area. This could set the basis to obtain fire risk maps using satellite data in near real-time. BEC has recently been chosen as an SMAP early adopter to foster the use of remotely sensed soil moisture data in forest fire risk prevention services.

Fine-scale SM maps were used in a recent collaborative study with the Centre for Ecological Research and Forestry Applications (CREAF) to analyse the possible impact of SM deficit in forest die-off episodes recorded in the last two years within the Catalonia region, and to identify the most vulnerable tree species. The results demonstrated that SMOS-derived 1-km soil moisture is a complementary variable to other meteorological drivers (e.g. precipitation, land surface temperature) in forest decline models; some of the studied tree species exhibit a high probability of forest die-off occurrence under persistent dry conditions, as seen by SMOS (Chaparro et al. 2014). Also, in collaboration with the Universitat de València, fine-scale SM estimates have been shown to be useful to account for short-term water stress on vegetation in model estimates of gross primary production (GPP) (SánchezRuiz et al. 2014b). The last version of the L4 product (v3.0) incorporates modelled land surface temperatures to provide all-weather capabilities (Piles et al. 2015); see Figure 17. This is expected to increase the applicability of the data in present (forest fires, forest die-off, GPP estimation) and foreseen (e.g. irrigation planning, agriculture) applications.

\section{The global water cycle: SSS and SM climatologies and teleconnections}

With almost six years of SMOS data, the analysis of the spatial and temporal variability of SM and SSS will start to shed light on how these two variables im-

$1 \mathrm{~km}$ Soil Moisture

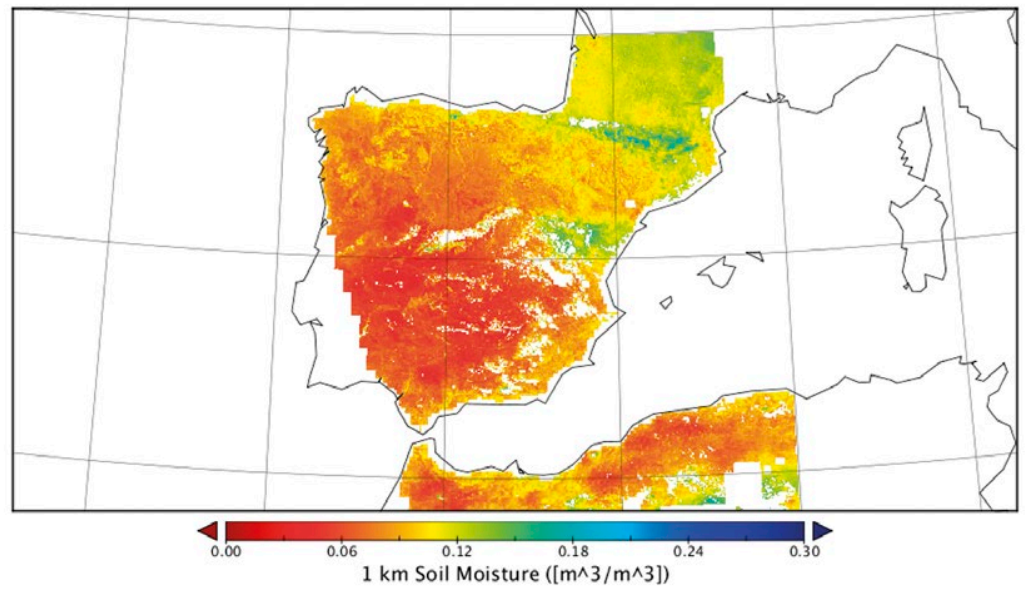

Fig. 17. - SMOS-BEC L4 product from 1 September 2014 (6 a.m.). 

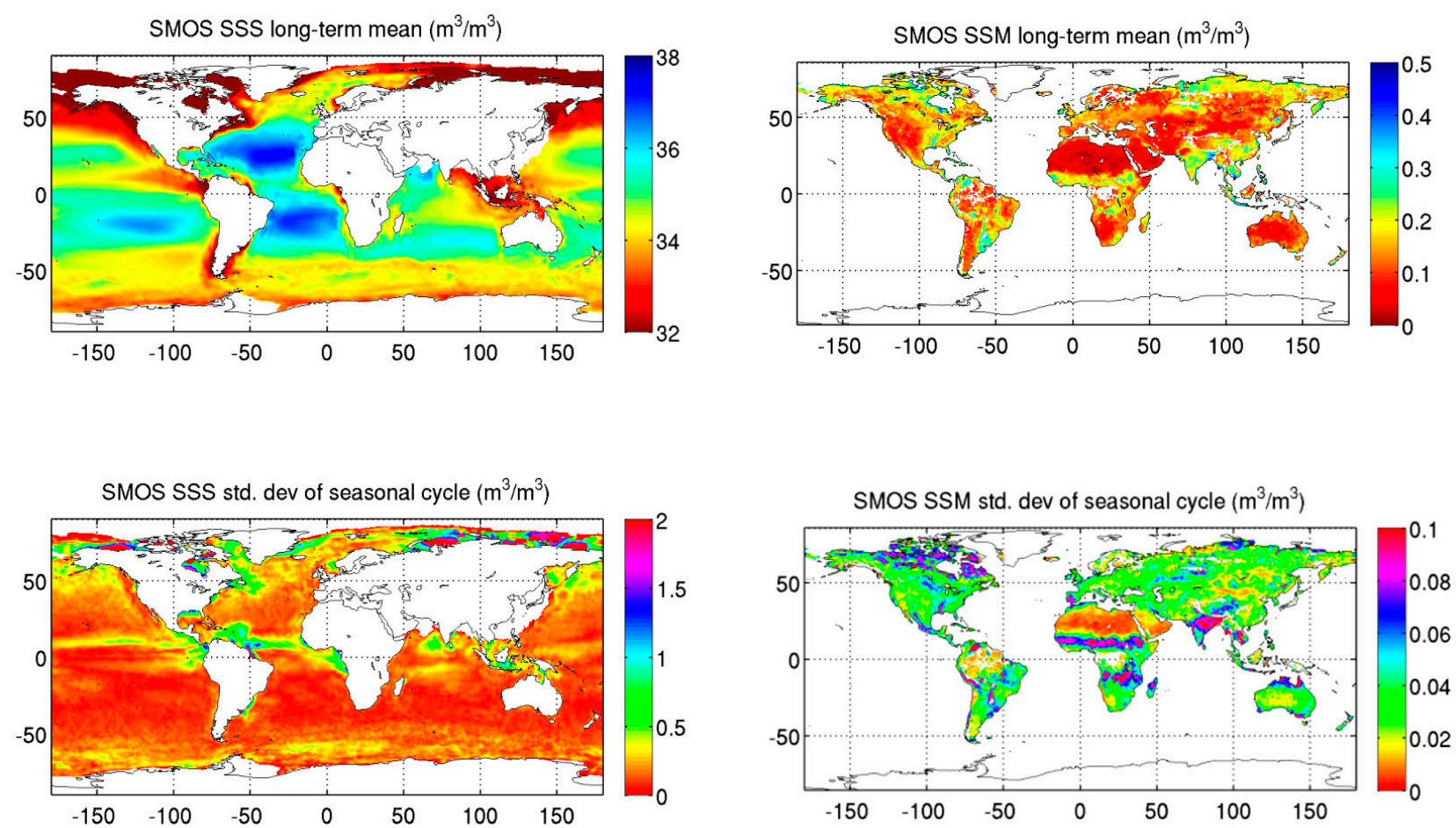

Fig. 18. - Top row: Average SSS (left) and SSM (right). Bottom row: Standard deviations of seasonal cycle of the variables on top.

pact the climate of the Earth's system at the global and the regional scale. The difficulty of characterizing the variability of both SM and SSS on a global scale using ground-based observations has prevented a realistic representation of the coupling between the land, the atmosphere and the oceans in current climate simulations. As a result, there is high uncertainty in climate projections. It is anticipated that the uncertainty of SM and SSS representation in climate models could be reduced using new satellite information, which will help improve future climate projections. The continuity of SM observational records will be provided by the NASA's SMAP mission (Entekhabi et al. 2010), launched in January 2015. Over the ocean, SSS has also been measured until very recently by the NASA's Aquarius mission (2011-2015) (Le Vine et al. 2007). These three missions have L-band radiometers on-board, which are optimal for SMOS remote sensing. SMAP will also have an L-band Synthetic Aperture Radar on-board to enhance the spatial resolution of SM estimates down to $10 \mathrm{~km}$. Aquarius had three additional scatterometers to correct for sea roughness effects in SSS retrievals.

Projections from present climate models show a strong coincidence in the global patterns, but there is still a considerable degree of ambiguity and difference between the various models. Both SM and SSS are key essential variables of the water cycle. The changes in salinity induced by the atmospheric influence on ocean surface (by means of the evaporation-precipitation balance) induces significant changes in sea water density and hence drives changes in the ocean thermohaline circulation. Regarding the influence of the ocean on the atmosphere, the latent heat of atmospheric water vapor critically conditions the circulation of the atmos- phere at scales ranging from individual thunderstorms to the global circulation of the atmosphere. Over land, regional- to global-scale projections of SM and evaporation remain uncertain. To date, there are still significant difficulties in modelling changes in the water cycle with enough accuracy to prevent modelled climate unrealistically drifting away from the observed climate. Hence, characterizing SM and SSS variations and their impacts on the Earth system are key to improve projections of climate change.

The SMOS mission is providing the first-ever global observations of SM over land and SSS over the oceans. With almost six years of mapping these two variables, it is now possible to start analysing their spatial variability at seasonal and inter-annual scales. A preliminary analysis has been performed to determine trends and anomalies in SMOS SM and SSS time series, analyse their spatial coherence and study their relationships through precipitation and evaporation (Fig. 18). By relating temporal series of SM and SSS anomalies to climate indices (i.e. North Atlantic Oscillation and El Niño/Southern Oscillation), it has been shown that SMOS data are able to reproduce most of the global patterns of weather alterations over land (areas affected by drought/heavy rain) and over the ocean (largest river plumes, salinity fluxes associated with eddy transport, etc.) (Piles et al. in press). SMOS SM and SSS climatologies have been obtained (annual climatologies are represented on the top row in Figure 18) and can be used as a basis for providing a better quantitative representation of these two variables in land surface models and ultimately for providing insight into the key role of fresh water variations in the climate system and its recent changes. 


\section{CONCLUSIONS}

The creation of BEC in 2007 has boosted Spanish $\mathrm{R}+\mathrm{D}$ activities in the processing of SMOS data and in other Earth observation missions. BEC has played a major role in the research and development of the algorithms used on SMOS data at all processing levels, with very significant contributions: to mention just a few, NS, ALL-LICEF (L1), model-independent OTT, generalized OTT schemes, empirical roughness models (L2), bias correction by SMOS climatologies, optimally interpolated maps (L3), multifractal fusion and pixel disaggregation (L4). All those studies have not only represented an improvement in the general quality of SMOS products but have led to new concepts in signal processing (e.g. new image reconstruction standards) and in the analysis of the dynamics of geophysical processes (e.g. the dynamic adjustment which is the basis of multifractal data fusion). Additionally, the work by BEC has led to the construction of the first integrated SM-SSS combined climatologies, which have been central for studying key teleconnections in the global water cycle, evidencing some asymmetric links that were previously unknown.

The growing involvement of BEC in other Earth Observations missions in L-band (Aquarius, SMAP) and its participation in ESA-led initiatives guarantees a successful continuation of the work started by Jordi Font 18 years ago.

\section{ACKNOWLEDGEMENTS}

This work was funded by the Spanish Ministry of Economy through the National R+D Plan by means of the MIDAS-7 project AYA2012-39356-C05-03 and previous grants. The validation part of this work was done with the support of the FP7-SPACE E-AIMS project (grant agreement 312642). The Argo data were collected and made freely available by the International Argo Programme and the national programmes that contribute to it (http://www.argo.ucsd.edu, http:// argo.jcommops.org). The Argo Programme is part of the Global Ocean Observing System.

\section{REFERENCES}

Antonov J.I., Seidov D., Boyer T.P., et al. 2010. World Ocean Atlas 2009, Salinity. In: Levitus S. (ed.) NOAA Atlas NESDIS 69 Vol. 2, U.S. Government Printing Office, Washington, D.C. $184 \mathrm{pp}$.

Argo. 2013. Argo quality control manual. V2. 9: 54 pp.

Ballabrera J., Hoareau N., Umbert M., et al. 2013. Tropical Pacific sea surface salinity variability derived from SMOS data: Comparison with in-situ observations. EGU General Assembly Conference Abstracts 15: 4928

Boutin J., Martin N., Yin X., et al. 2012. First assessment of SMOS data over open ocean. Part II - Sea surface salinity. IEEE Trans. Geosci. Remote Sens. 50(5): 1662-1675. http://dx.doi.org/10.1109/TGRS.2012.2184546

Blower J., Haines K., Santokhee A., et al. 2009. Godiva2: Interactive visualization of environmental data on the web. Phil. Trans. Roy. Soc. A, 367: 1035-1039. http://dx.doi.org/10.1098/rsta.2008.0180

Bretherton F.P., Davis R.E., Fandry C.B. 1976. A technique for objective analysis and design of oceanographic experiments applied to MODE-73. Deep-Sea Res. 23: 559-582.

Camps A., Font J., Vall-1lossera M., et al. 2004. The WISE 2000 and
2001 Campaigns in Support of the SMOS Mission: Sea Surface L-band Brightness Temperature Observations and their Application to Multi-Angular Salinity Retrieval. IEEE Trans. Geosci. Remote Sens. 42: 804-823. http://dx.doi.org/10.1109/TGRS.2003.819444

Camps A., Gabarró C., Vall-llossera M., et al. 2016. From field experiments to salinity products: a tribute to the contributions of Jordi Font to the SMOS mission. Sci. Mar. 80S1: 159-172. http://dx.doi.org/10.3989/scimar.04285.04A

Chaparro D., Vayreda J., Martinez-Vilalta J., et al. 2014. SMOS and climate data applicability for analyzing forest decline and forest fires. Geosci. Remote Sens. Symp. (IGARSS). 2014 IEEE Int. 13-18 July 2014. 1069-1072. http://dx.doi.org/10.1109/IGARSS.2014.6946613

Chaparro D., Vall-llossera M., Piles M., et al. 2015. Low Soil Moisture and High Temperatures as indicators for Forest Fire Ocurrence and Extent across the Iberian Peninsula. Geosci. Remote Sens. Symp. (IGARSS). 2015 IEEE Int. 26-31 July 2015. 3325-3328.

http://dx.doi.org/10.1109/IGARSS.2015.7326530

Comiso J.C., Cavalieri D.J., Markus T. 2003. Sea ice concentration, ice temperature, and snow depth using AMSR-E data. IEEE Trans. Geosci. Remote Sens. 41(2): 243-252. http://dx.doi.org/10.1109/TGRS.2002.808317

Corbella I., Torres F., Camps A., et al. 2005. MIRAS end-to-end calibration: application to SMOS L1 processor. IEEE Trans. Geosci. Remote Sens. 43: 1126-1134. http://dx.doi.org/10.1109/TGRS.2004.840458

Corbella I., Torres F., Duffo N., et al. 2011. MIRAS Calibration and Performance: Results From the SMOS In-Orbit Commissioning Phase. IEEE Trans. Geosci. Remote Sens. 49: 3147-3155. http://dx.doi.org/10.1109/TGRS.2010.2102769

Corbella I., Torres F., Wu L., et al. 2013. Spatial Biases Analysis and Mitigation Methods in SMOS Images. Geosci. Remote Sens. Symp. (IGARSS). 2013 IEEE Int. 21-26 July 2013. 3415-3418. http://dx.doi.org/10.1109/IGARSS.2013.6723562

Corbella I., Duran I., Wu L., et al. 2015. Impact of Correlator Efficiency Errors on SMOS Land-Sea Contamination. IEEE Geosci. Remote Sens. Lett. 99: 1-5. http://dx.doi.org/10.1109/LGRS.2015.2428653

Crapolicchio R. 2008. TEC usage for the SMOS Level 1 Operational Processor. Tech. rept. XSMS-GSEG-EOPG-TN-06-0019.

Daganzo-Eusebio E., Oliva R., Kerr Y., et al. 2013. SMOS radiometer in the 1400-1427 MHz passive band: Impact of the RFI environment and approach to its mitigation and cancellation. IEEE Trans. Geosci. Remote Sens. 51: 4999-5007. http://dx.doi.org/10.1109/TGRS.2013.2259179

Entekhabi D., Njoku E., O’Neill P., et al. 2010. The Soil Moisture Active Passive (SMAP) mission. Proc. IEEE. 98: 704-716. http://dx.doi.org/10.1109/JPROC.2010.2043918

Font J., Camps A., Borges A., et al. 2010a. SMOS: The challenging Sea Surface Salinity Measurement from Space. Proc. IEEE. 98: 649-665. http://dx.doi.org/10.1109/JPROC.2009.2033096

Font J., Boutin J., Reul N., et al. 2010b. SMOS objectives and approach for ocean salinity observations. Proc. ESA Liv. Planet Symp., Bergen, Norway, Jun. 28-Jul. 2, 2010, ESA SP-686.

Gabarró C., Font J., Camps A., et al. 2004. A new empirical model of the sea surface microwave emissivity for the salinity remote sensing. Geoph. Res. Lett. 31.

Gabarró C., Font J., Miller J., et al. 2008. The usage of a semiempirical emissivity model for a rough estimation of sea surface salinity from an airborne microwave radiometer. Sci. Mar. 72: 329-336.

http://dx.doi.org/10.3989/scimar.2008.72n2329

Gabarró C., Portabella M., Talone M., et al. 2009. Towards an Optimal SMOS Ocean Salinity Inversion Algorithm. Geosci. Remote Sens. 6: 509-513. http://dx.doi.org/10.1109/LGRS.2009.2018490

Gabarró C., González-Gambau V., Corbella I., et al. 2013. Impact of the Local Oscillator Calibration Rate on the SMOS Measurements and Retrieved Salinities. IEEE Trans. Geosci. Remote Sens. 51(9): 4633-4642. http://dx.doi.org/10.1109/TGRS.2012.2233744

Gabarró C., Pla Q., Elosegui P., et al. 2015. Investigating SMOS data for sea ice concentration determinatation. SMOS Sci.Work.

González-Gambau V. Corbella I. Torres F. et al 2014. Latitudinal and seasonal SMOS amplitude calibration assessment. Geosci. Remote Sens. Symp. (IGARSS). 2014 IEEE Int. 13-18 July 2014. 1917-1920. 
http://dx.doi.org/10.1109/IGARSS.2014.6946833

González-Gambau V., Turiel A., Olmedo E., et al. 2016. Nodal Sampling: A New Image Reconstruction Algorithm for SMOS. IEEE Trans. Geosci. Remote Sens. 54: 2314-2328. http://dx.doi.org/doi: 10.1109/TGRS.2015.2499324

González-Zamora A., Sánchez N., Martínez-Fernández J., et al. 2015. Long-term SMOS soil moisture products: a comprehensive evaluation across scales and methods in the Duero Basin (Spain). J. Phys. Chem. Earth. 83-84: 123-136. http://dx.doi.org/10.1016/j.pce.2015.05.009

Gourrion J., Guimbard S., Portabella M., et al. 2013. Toward an Optimal Estimation of the SMOS Antenna-Frame Systematic Errors. IEEE Trans. Geosci. Remote Sens. 51(9): 4752-4760. http://dx.doi.org/10.1109/TGRS.2013.2271593

Grodsky S.A., Reul N., Lagerloef G., et al. 2012. Haline hurricane wake in the Amazon/Orinoco plume: AQUARIUS/SACD and SMOS observations. Geoph. Res. Lett. 39: L20603. http://dx.doi.org/10.1029/2012GL053335

Guimbard S., Gourrion J., Portabella M., et al. 2012. SMOS SemiEmpirical Ocean Forward Model Adjuntment. IEEE Trans. Geosci. Remote Sens. 50(5): 1676-1687. http://dx.doi.org/10.1109/TGRS.2012.2188410

Huntemann M., Heygster G., Kaleschke L., et al. 2013. Empirical sea ice thickness retrieval during the freeze-up period from SMOS high incident angle observations. The Cryosphere 8: 439-451. http://dx.doi.org/10.5194/tc-8-439-2014

Jordà G., Gomis D. 2009. Towards SMOS L4 SSS products: Improving L3 SSS with auxiliary SSS data. IEEE Trans. Geosci. Remote Sens. 48: 2204-2214. http://dx.doi.org/10.1109/TGRS.2009.2037899

Kaleschke L., Lupkes C., Vihma T., et al. 2001. SSM/I Sea ice remote sensing for mesoscale ocean-atmosphere interaction analysis. Can. J. Remote Sens. 27(5): 526-537. http://dx.doi.org/10.1080/07038992.2001.10854892

Kaleschke L., Maaß N., Haas C., et al. 2010. A sea-ice thickness retrieval model for $1.4 \mathrm{GHz}$ radiometry and application to airborne measurements over low salinity sea-ice. The Cryosphere 4: $583-592$ http://dx.doi.org/10.5194/tc-4-583-2010

Kaleschke L., Tian-Kunze X., Maaß N., et al. 2012. Sea ice thickness retrieval from SMOS brightness temperatures during the Arctic freeze-up period. Geoph. Res. Lett. 39: L05501. http://dx.doi.org/10.1029/2012GL050916

Kerr Y., Waldteufel P., Wigneron J.P., et al. 2010. The SMOS mission: New Tool for Monitoring Key Elements of the Global Water Cycle. Proc. IEEE. 98: 666-687. http://dx.doi.org/10.1109/JPROC.2010.2043032

Klein L., Swift C. 1977. An Improved Model for the Dielectric Constant of Sea Water at Microwave Frequencies. IEEE Trans. Ant. Prop. 25: 104-111. http://dx.doi.org/10.1109/TAP.1977.1141539

L1 team. 2015. Definition of a metric to assess SMOS L1 Data Quality, SM-TN-AURO-L1OP-0003, ESA Tech. rept.

Le Vine D.M., Lagerloef G.S.E., Colomb F.R., Yueh S.H., Pellerano F.A. 2007. Aquarius: An Instrument to Monitor Sea Surface Salinity From Space. IEEE Trans. Geosci. Remote Sens. 45(7): 2040-2050 http://dx.doi.org/10.1109/TGRS.2007.898092

McCulloch M.E., Spurgeon P., Chuprin A. 2011. Have mid-latitude ocean rain-lenses been seen by the SMOS satellite? Ocean Model. 43: 108-111.

McMullan K.D., Brown M.A., Martín-Neira M., et al. 2008. SMOS the payload. IEEE Trans. Geosci Remote Sens. 46(3): 594-605. http://dx.doi.org/10.1109/TGRS.2007.914809

Meirold-Mautner I., Mugerin C., Vergely J., et al. 2009. SMOS ocean salinity performance and TB bias correction. EGU Gen. Assem.

Oliva R., Daganzo E., Kerr Y., et al. 2012. SMOS Radio Frequency Interference scenario: Status and actions taken to improve the RFI environment in the 1400-1427 MHz passive band. IEEE Trans. Geosci. Remote Sens. 50(5): 1427-1439. http://dx.doi.org/10.1109/TGRS.2012.2182775

Oliva R., Martín-Neira M., Corbella I., et al. 2013. SMOS calibration and instrument performance after one year in orbit. IEEE Trans. Geosci. Remote Sens. 51(1): 654-670 http://dx.doi.org/10.1109/TGRS.2012.2198827

Park H., González-Gambau V., Camps A. 2015. High angular resolution RFI localization in synthetic aperture interferometric radiometers using Direction of Arrival estimation. IEEE Geosci.
Remote Sens. Lett. 12(1): 102-106. http://dx.doi.org/10.1109/LGRS.2014.2327006

Piles M., Camps A., Vall-llossera M., et al. 2011. Downscaling SMOS-derived soil moisture using MODIS visible/infrared data. IEEE Trans. Geosci. Remote Sens. 49: 3156-3166. http://dx.doi.org/10.1109/TGRS.2011.2120615

Piles M., Vall-llossera M., Camps A., et al. 2013. On the synergy of SMOS and Terra/Aqua MODIS: high resolution soil moisture maps in near real-time. Geosci. Remote Sens. Symp. 2013 IEEE Int. 21-26 July 2013. 3423-3426. http://dx.doi.org/10.1109/IGARSS.2013.6723564

Piles M., Sánchez N., Vall-llossera M. et al. 2014. A downscaling approach for SMOS land observations: two year evaluation of high resolution soil moisture maps over the Iberian Peninsula. IEEE J. Sel. Top. App. Earth Observ. Remote Sens. 7(9): 3845-3857. http://dx.doi.org/10.1109/JSTARS.2014.2325398

Piles M., Pou X., Camps A., et al. 2015. Quality report: validation of SMOS-BEC L4 high resolution soil moisture products, version 3.0 or "all-weather", Tech. rept. http://cp34-bec.cmima.csic.es/doc/BEC-SMOS-L4SMv3-QR. pdf.

Piles M., Martínez E., Ballabrera J., et al. In press. Estimation of global soil moisture seasonal variability using SMOS satellite observations. Proc. Rec. Adv. Quant. Remote Sens. 396-400.

Reul N., Tenerelli J., Chapron B., et al. 2007. Modeling Sun Glitter at L-Band for Sea Surface Salinity Remote Sensing With SMOS. IEEE Trans. Geosci. Remote Sens. 45: 2073-2087. http://dx.doi.org/10.1109/TGRS.2006.890421

Reul N., Tenerelli J., Chapron B., et al. 2012. SMOS satellite Lband radiometer: A new capability for ocean surface remote sensing in hurricanes. J. Geophys. Res. 117: C02006. http://dx.doi.org/10.1029/2011JC007474

Reul N., Quilfen Y., Chapron B., et al. 2014. Multisensor observations of the Amazon-Orinoco river plume interactions with hurricanes. J. Geophys. Res. Oceans. 119: 8271-8295. http://dx.doi.org/10.1002/2014JC010107

Sánchez N., Piles M., Martínez-Fernández J., et al. 2014. Hyperspectral Optical, Thermal and Microwave L-band Observations for Soil Moisture Retrieval at Very High Spatial Resolution. Photogram. Eng. Remote Sens. 80: 745-755. http://dx.doi.org/10.14358/PERS.80.8.745

Sánchez N., Alonso-Arroyo A., Martínez-Fernández J., et al. 2015. On the Synergy of Airborne GNSS-R and Landsat 8 for Soil Moisture Estimation. Remote Sens. 7: 9954-9974. http://dx.doi.org/10.3390/rs70809954

Sánchez-Ruiz S., Piles M., Sánchez N., et al. 2014. Combining SMOS with visible and near/shortwave/thermal infrared satellite data for high resolution soil moisture estimates. J. Hydrol. 49: 3156-3166 http://dx.doi.org/10.1016/j.jhydrol.2013.12.047

Sánchez-Ruiz S., Moreno A., Martínez B., et al. In press. Impact of water stress on GPP estimation from remote sensing data in Mediterranean ecosystems. Proc. Rec. Adv. Quant. Remote Sens. pp. 338-343.

Slominska E., Gabarro C., Marczewski W., et al. 2015. Observations of Antarctic icebergs acquired with the SMOS satellite. SMOS Sci. Work.

Stoffelen A. 1998. Toward the true near surface wind speed: Error modeling and calibration using triple collocation. J. Geophys. Res. 103: 7755-7766. http://dx.doi.org/10.1029/97JC03180

Talone M., Camps A., Mourre B., et al. 2009. Simulated SMOS Level 2 and 3 Products: the Effect of Introducing ARGO Data in the Processing Chain and its Impact on the Error Induced by the Vicinity of the Coast. IEEE Trans. Geosci. Remote Sens. 47: 3041-3050 http://dx.doi.org/10.1109/TGRS.2008.2011618

Talone M., Sabia R., Camps A., et al. 2010. Sea surface salinity retrievals from HUT-2D L-band radiometric measurements. Remote Sens. Environ. 114:1756-1764. http://dx.doi.org/10.1016/j.rse.2010.03.006

Talone M., Gabarró C., Camps A., et al. 2011. Error covariance matrices characterization in the ocean salinity retrieval cost function within the SMOS mission. J. Atmosp. Oce. Tech. 28: 1155-1166. http://dx.doi.org/10.1175/2011JTECHO813.1

Tenerelli J., Reul N. 2010. Analysis of L1PP Calibration Approach Impact in SMOS TBs and 3-Days SSS Retrievals over the Pacific Using an Alternative Ocean Target Transformation Ap- 
plied to L1OP Data. Tech. rept. IFREMER/CLS.

Tenerelli J., Reul N., Mouche A., et al. 2008. Earth-Viewing LBand Radiometer Sensing of Sea Surface Scattered Celestial Sky Radiation-Part I: General Characteristics. IEEE Trans. Geosci. Remote Sens. 46: 659-674.

http://dx.doi.org/10.1109/TGRS.2007.914803

Thébault E., Finlay C., Beggan C., et al. 2015. International Geomagnetic Reference Field: the 12th generation. Earth, Planets and Space. 67: 79 . http://dx.doi.org/10.1186/s40623-015-0228-9

Torres F., Camps A., Bara J., et al. 1996. On-board phase and modulus calibration of large aperture synthesis radiometers: Study applied to MIRAS. IEEE Trans. Geosci. Remote Sens. 34: 1000-1009. http://dx.doi.org/10.1109/36.508417

Torres F., González-Gambau V., González-Haro C. 2008. Onepoint calibration in interferometric radiometers devoted to Earth observation. Proc. SPIE Europe Remote Sens. http://dx.doi.org/10.1117/12.800078

Turiel A., Yahia H., Pérez-Vicente C.J. 2008. Microcanonical
Multifractal Formalism: a geometrical approach to multifractal systems. Part I: Singularity Analysis. J. Phys. A. 41: 015501. http://dx.doi.org/10.1088/1751-8113/41/1/015501

Turiel A., Nieves V., García-Ladona E., et al. 2009. The multifractal structure of satellite temperature images can be used to obtain global maps of ocean currents. Oce. Sci. 5: 447-460. http://dx.doi.org/10.5194/os-5-447-2009

Umbert M., Hoareau N., Turiel A., et al. 2014. New blending algorithm to synergize ocean variables: The case of SMOS sea surface salinity maps. Remote Sens. Environ. 146: 172-187. http://dx.doi.org/10.1016/j.rse.2013.09.018

Umbert M., Guimbard S., Lagerloef G., et al. 2015. Detecting the surface salinity signature of Gulf Stream cold-core rings in Aquarius synergistic products. J. Geoph. Res. 120: 859-874. http://dx.doi.org/10.1002/2014JC010466

Zine S., Boutin J., Font J., et al. 2008. Overview of the SMOS sea surface salinity prototype processor. IEEE Trans. Geosci. Remote Sens. 46: 621-645.

http://dx.doi.org/10.1109/TGRS.2008.915543 